\title{
MEDIDAS OFENSIVAS Y DEFENSIVAS DE LOS VECINOS DE SONORA EN RESPUESTA A LAS \\ INCURSIONES APACHES, 1854-1890. EL DESPLIEGUE DE UNA AUTODEFENSA LIMITADA
}

\author{
Amparo Angélica Reyes Gutiérrez \\ Ignacio Almada Bay \\ David Contreras Tánori \\ El Colegio de Sonora
}

INTRODUCCIÓN

Ena de Sonora de $1833^{1}$ a 1890 fue escenario de violencia
intermitente entre nómadas de lengua atapascana -denomi-
nados apaches- y los vecinos de los asentamientos -cuya
población estaba formada por mestizos, indios y blancos-,
incluidos sus aliados del tronco lingüístico uto-azteca, como

Fecha de recepción: 6 de diciembre de 2014

Fecha de aceptación: 20 de abril de 2015

${ }^{1}$ Desde la década de 1820 distintas parcialidades apaches asentadas de paz alrededor de los presidios de Sonora iniciaron alzamientos con el argumento de que el gobierno mexicano intentaba quitarles las raciones que se les otorgaban desde fines del siglo xvirI. Fue en 1833 cuando se extendió por los asentamientos de paz una rebelión cuyos niveles de violencia fueron en aumento. Sus consecuencias llegaron hasta la década de 1880; Almada, Diccionario, p. 60. 
los ópatas y los tohono o'odham -el pueblo del desierto-, llamados "pápagos", ambos con un historial de agravios como para comportarse como enemigos de los apaches. ${ }^{2}$

El carácter del conflicto de violencia intermitente remite a una guerra fronteriza ${ }^{3}$ de carácter étnico, desplegada en ciclos de hostilidades mediante espirales de represalias, que no distingue entre la población no combatiente y la combatiente, que toma mujeres, niñas y niños como cautivos y botín-los apaches eligieron caballos y posteriormente ganado vacuno, éste para intercambiarlo con comerciantes asentados en Estados Unidos que lo demandaban-; desagregada, es decir, sostenida entre bandas de apaches y comunidades de vecindarios, que proceden como colectividades no compactas ni homogéneas, que están en guerra con unas y en paz con otras; unidades desagregadas que no siguen un mando centralizado y que privilegian las relaciones personales -entre 1830 y 1870 es común que la banda chiricahua esté en guerra con la población de Sonora y comerciando en paz con la del estado de Chihuahua-; ${ }^{4}$ y asimétrica en la capacidad de fuego: entre 1850 y 1890, los atapascanos tienen acceso a mercados para intercambiar mulas, ganado vacuno

${ }^{2}$ Confrontaciones entre o'odham y apaches en Jасову, Shadows at Dawn, pp. 20-24 y SweEney, From Cochise to Geronimo, p. 540; los apaches como enemigos de los ópatas en Yetman, The Ópatas, pp. 76, 126, 167, 210-212, 215, 220 y 248.

3 Antes del trazado de la frontera de México con Estados Unidos, efectuado a partir de 1849 , este espacio fue considerado parte de la periferia, ubicado en los confines septentrionales de la Monarquía hispánica en el continente americano y posteriormente en el lejano norte mexicano.

${ }^{4}$ Esta pauta se puede observar en SweEney, Mangas Coloradas, pp. 187219 y 335-362; Griffen, Apaches, pp. 185-265 y 267-268; y Griffen, Utmost Good Faith, pp. 181-249. 
y caballos sustraídos de Sonora por armas de fuego de repetición, con comerciantes de Nuevo México y Arizona, gracias a la tolerancia de oficiales del ejército estadounidense, en contraste con las armas primitivas y el parque escaso de los vecinos de Sonora. ${ }^{5}$

Conflicto de violencia intermitente que propició una "recíproca especialización en la violencia", 6 que favoreció el papel de intermediarios culturales -como los excautivos-y la existencia de periodos de paz parcial -como la vivida en los campamentos de apaches de paz contiguos al fuerte de Fronteras, donde decenas de atapascanos fueron bautizados y aprendieron rudimentos de español- en las rancherías levantadas por guerreros chiricahuas y sus familias alrededor del expresidio de Janos, en la frontera del noroeste de Chihuahua con Sonora, sitios donde por décadas ocurrieron intercambios entre población de lengua atapascana y población de habla española.

\section{PREÁMBULO METODOLÓGICO}

El propósito de este artículo es examinar las respuestas organizadas de carácter bélico de los vecinos de los asentamientos ubicados en el estado de Sonora a las incursiones apaches, identificadas en fuentes primarias, agrupándolas por su denominación contemporánea a los hechos o su índole semejante, hasta configurar una tipología de medidas ofensivas y defensivas. Tipología que confirma la reportada

5 Smith, “The Scalp Hunter”, p. 8; DeLay, War, pp. 198-199 y 212225; Vandervort, Indian Wars, pp. 44-45; Jacoby, Shadows at Dawn, pp. 101-105 y 163-165.

${ }_{6}$ Alonso, Thread of Blood, p. 30. 
por otros autores para el noreste del país. ${ }^{7}$ Esta indagación registra 12 medidas ofensivas y cuatro defensivas en un contexto de autodefensa limitada por no contar con el apoyo del ejército nacional ni con un flujo de recursos para equipar las fuerzas locales, como también por advertirse la frontera con Estados Unidos como un lindero que se debía respetar; de no hacerlo podrían sobrevenir calamidades mayores. ${ }^{8} \mathrm{La}$ circulación de la tipología propuesta y su desglose en medidas específicas estimulará su identificación y empleo en otros espacios fronterizos, como también la discusión acerca de su sentido y alcances.

En cuanto al diseño metodológico y las técnicas de investigación, se seleccionó un periodo de 36 años, 1854-1890,

7 En Coahuila, “[...] las autoridades regionales y locales [...] junto con los vecinos, establecieron estrategias defensivas y ofensivas [...]”, véase Rodríguez, La guerra, 59; Sánchez Moreno señala acerca del área de Coahuila próxima al río Bravo: "Desde las haciendas y ranchos también se debían realizar acciones punitivas contra los agresores, organizando pequeñas unidades compuestas por lugareños de otras propiedades rurales cercanas. [...], en este caso no debían sobrepasar los límites de la hacienda o rancho dañado [...]". Estas acciones se realizarían por "la partida expedicionaria local" en un esquema de "contraofensivas coordinadas entre las fuerzas militares y los grupos de vecinos de las diferentes municipalidades", y en un contexto de "autodefensa limitada", que respaldarían planes de defensa nacionales y estatales y la implantación de colonias militares hacia 1851-1853; SÁnchez Moreno, “Apolinario Moreno”, pp. 86-91.

${ }^{8}$ Los acuerdos para el paso recíproco de tropas a través de la frontera se establecieron a partir de 1882. Cabe observar que las expediciones de Sonora a Arizona fueron excepcionales, por breves días y en un radio de acción reducido, en coordinación con la tropa estadounidense apostada en el fuerte de Calabazas. La mayoría de estas incursiones fueron hechas por guerreros pápagos adscritos a la Guardia Nacional. RIA, AGES, $E, P$, t. 434, 1871, Prefectura de Moctezuma, Moctezuma, 10 de enero de 1871. 
con base en la disponibilidad de fuentes primarias, y se elaboró una base de datos con 4092 registros extraídos de los ramos Prefecturas e Indígenas, ambos del fondo Ejecutivo del Archivo General del Estado de Sonora.

Las fuentes de ambos ramos fueron generadas por autoridades locales -desde el celador, la autoridad con el espacio y el rango más diminutos, hasta el presidente municipal, pasando por los jueces locales- electas cada año, que podían ser reelectas. ${ }^{9}$

La visión de los vecinos es desplegada aquí y su elaboración sigue este patrón: parte de un informe de hechos transmitidos por testigos presenciales a una autoridad local que lo comunica al prefecto de distrito y éste al gobernador o secretario de Estado. La respuesta usual, mediada por la autoridad local, en los hechos, es rastrear y hostilizar a los apaches por ciudadanos armados que forman la Guardia Nacional y cuentan con prerrogativas como elegir a sus jefes y el derecho a la "saca": a quedarse, previo trámite, con una porción del ganado que habían quitado a los apaches y que conducían como botín a Estados Unidos.

Una parte significativa de los asentamientos incluidos en este inventario de daños atribuidos a las incursiones apaches y de los accidentes naturales que se dan como señas, hubiera permanecido en el olvido, si no es por los conflictos entre apaches y vecinos, que los plasmaron en documentos que esta indagación saca a la luz.

El grueso de la población, ubicada en los distritos fronterizos de Sonora con Estados Unidos y con el estado de Chihuahua, era poco instruida -la grafía de los documentos

${ }^{9}$ Almada y Luna, Sonora Historia, t. I, pp. 110-115; t. II, pp. 41-47. 
revela que los vecinos escribían como oían-, dependía del propietario del rancho o hacienda, que era a la vez la autoridad designada por la constitución local como celador o comisario de policía para velar por el orden, y cuya autoridad social se basaba en la galera que poseía como almacén de granos para la recurrente época de escasez, que la sequía o el exceso de lluvias provocaban irremediablemente cada cinco o siete años.

Consideramos como vecinos a la población que habitaba los asentamientos ubicados en el estado de Sonora en el periodo 1854-1890, de estatus y magnitud distintos: cabecera de distrito, villa, cabecera municipal, pueblo, congregación, hacienda y rancho. La población de estos asentamientos en el periodo de estudio está cohesionada por un enemigo común externo -los apaches-. Los antiguos presidios coloniales son los asentamientos emblemáticos, pero no los únicos, de una especialización en la violencia y una militarización de la vida cotidiana. La población es resultado de una mezcla incesante y está constituida mayormente por mestizos, y en menor cantidad por indios asimilados, criollos y mulatos. ${ }^{10}$

En el espacio identificado como Sonora se había desarrollado un conjunto de prácticas y de intereses

[...] que se tradujeron en una cultura de excepción e inmunidad, al considerarse sus pobladores exceptuados del pago del tributo, del diezmo eclesiástico y otros gravámenes, por ostentarse como defensores del territorio o de la frontera en el combate de indios no sometidos -como apaches y seris-,

${ }^{10}$ Jaсову, Shadows at Dawn, pp. 51 y 54. 
de indios misionales o ex misionales rebeldes y de filibuste$\operatorname{ros}[\ldots] .{ }^{11}$

En ese territorio florece una cultura que tiene "[...] predilección por los hechos consumados, por las soluciones $d e$ facto y no de jure"; donde el tejido social estaba

[...] inmerso en un universo relacional a base de arreglos mutuos e informales, donde la parentela y la comunidad territorial tienen un protagonismo relevante y actúan como fuerzas disciplinadoras locales [...]. El orden local es resultado de una interacción entre grupos étnicos fuertes, una población blanca minoritaria y dispersa y una débil presencia estatal, donde ningún actor controla de manera dominante el entorno; disgregación del poder que corresponde a un proceso de ocupación del espacio a base de asentamientos intercalados o fugaces $[\ldots]^{12}$

En el lapso de estudio, 1854-1890, se constata en Sonora la participación de la Guardia Nacional formada por vecinos que están en el periodo de servicio como integrantes de ella o que se suman como voluntarios. Un proceso parecido se ha documentado para el noroeste de Chihuahua, protagonizado por "las milicias armadas de los pueblos" que practican la guerra de guerrillas y son resultado de la organización de la comunidad para sostener una resistencia prolongada, como parte de una cultura de guerra desarrollada en las comunidades campesinas fronterizas del siglo XIX, ante las incursiones apaches. ${ }^{13}$

11 Almada Bay, “Ilícitos”, p. 203.

12 Almada Bay, “Ilícitos”, pp. 204 y 208.

13 Lloyd, "Milicias pueblerinas”, pp. 126-127. 
El conflicto entre los vecinos de Sonora y los apaches -en especial los chiricahuas- incluye una dimensión territorial cuya dinámica es importante. Las "gentes" o nnee, como se autollamaban los apaches, han sido vistas por la historiografía académica reciente como "una constelación de distintas comunidades" que habitaba "un espacio repleto de lugares específicos que evocan momentos diferentes de su historia".

La memoria colectiva transgeneracional de las "gentes" o nnee confirma que pertenecen a la familia lingüística atapascana, que siguieron una trayectoria norte sur, migrando en el curso de muchas generaciones desde latitudes boreales hasta el espacio ocupado y disputado -según las fuentes españolas- desde los siglos XVI y XVII, absorbiendo en este proceso migratorio a comunidades preexistentes con quienes formaron una amalgama que sería denominada por los españoles como apaches. Las "gentes" o nnee, en sus fuentes orales históricas, reconocen nexos entre ellos y grupos vecinos como los posteriormente conocidos como navajos, hopi y zuni. ${ }^{14}$

Los hombres de los clanes y bandas atapascanos aportaban piezas de cacería para la subsistencia colectiva. A fines del siglo xvir, los hombres nnee dieron un giro a la caza, pasando a incursionar entre sus vecinos por alimentos, en especial mamíferos de gran tamaño, hasta hace poco desconocidos para ellos, como el caballo, que anticiparon o acompañaron el arribo de los españoles a la región.

Las gentes o nnee, que desconocían la propiedad privada, advirtieron la dispersión de caballos, ganado, ovejas y cabras montaraces y la multiplicación de los ubicados en los asentamientos de vecinos como piezas de cacería

${ }^{14}$ Jасову, Shadows at Dawn, pp. 144-148. 
disponibles como alimento, y el caballo también como medio de guerra, estatus y transporte. Por su parte, los vecinos tomaron como actos hostiles la sustracción de los animales, que consideraban suyos, por los apaches. Éstos empezaron a hacer redadas en las proximidades y lejanas incursiones para proveerse de alimento, en un principio evitando la confrontación.

La guerra se desarrolló por los atapascanos como respuesta a la pérdida de un familiar a manos de los españoles y su objeto era infligir muertes, tomar mujeres, niñas y niños como cautivos, y bienes, como caballos, considerados como despojos o botín. La respuesta de los españoles fueron las deportaciones y las expediciones punitivas a los aduares o refugios estacionales de los apaches, lo que contribuyó a un ciclo de "incursiones y contraincursiones", a una escalada de represalias que incluyeron la mutilación y el desmembramiento de algunos nnee, en un marco de mutua aniquilación. ${ }^{15}$

Las confrontaciones dieron mayor importancia a las incursiones y a la guerra por los apaches y afectaron su modo de vida. Así, la preferencia de los nnee por habitar terreno montañoso en sus desplazamientos estacionales fue reforzada por el acceso que ofrecía a una diversidad de nichos ecológicos -con manantiales, sombra, pastura y escondites en cañones con paredes verticales y barrancos de fuerte pendiente-, para protegerse en esos laberintos de sus enemigos blancos y nativos como comanches, ópatas y pápagos, por contar con cuevas donde guardar armas, aparejos, sillas de montar y alimentos y sobrevivir al agobiante

${ }^{15}$ Jacoвy, Shadows at Dawn, pp. 148-155. 
calor del verano y a las temperaturas extremas de la faja semidesértica de la región. ${ }^{16}$

A lo largo del siglo xIx, se celebraron treguas o acuerdos de paz parcial entre jefes de bandas y clanes nnee y comunidades de vecinos, basados en arreglos precarios, que frecuentemente terminaban en una masacre que tomaba por sorpresa a una de las partes. Los establecimientos de paz para los apaches fueron la fórmula pacífica más estable que funcionó desde fines del siglo xviII, basados en la provisión de raciones alimenticias, cobijas, alcohol y naipes. Sin embargo, desaparecieron en el primer tercio del siglo xix por la falta de recursos del gobierno nacional mexicano, propiciando que los nnee reemprendieran las depredaciones.

Los chiricahuas y los vecinos de Sonora desarrollaron una mutua hostilidad, fundada en masacres atribuidas a traiciones o ataques por sorpresa. Este proceso dio inicio en la primavera de 1831 y contrastaba con la relativa paz entre los chiricahuas y los vecinos de Chihuahua. El gobierno de Sonora recurrió al empleo de mercenarios, a las recompensas por cueros cabelludos y a la "saca", con la idea de exterminar o contener a los chiricahuas. Una interminable espiral de represalias alimentó este proceso, que concluyó en septiembre de 1886 con la entrega del jefe chiricahua Gerónimo al ejército estadounidense. Como un ejemplo de las consecuencias territoriales de este conflicto, en la década de 1830, por cerca de seis años, una porción considerable alrededor del antiguo presidio de Fronteras fue habitada por chiricahuas que expulsaron o acabaron con la población de vecinos. ${ }^{17}$

16 Jacoby, Shadows at Dawn, pp. 154-155; SweEneY, From Cochise to Geronimo, p. 241.

17 Sweeney, Mangas Coloradas, pp. 44-219. 
La dimensión territorial del conflicto apaches-vecinos también se puede apreciar en los ataques que, por décadas, entre 1850 y 1886, hicieron los chiricahuas a los asentamientos de vecinos, utilizando como corredores los seis valles longitudinales fluviales más las serranías adyacentes -donde levantaron rancherías que disputaban a los vecinos el control del territorio- que forman la esquina noreste de Sonora. ${ }^{18}$

Como la práctica que, entre 1881 y 1886, la banda chiricahua a la que pertenecía Gerónimo realizaba al cruzar la frontera en ambos sentidos, refugiándose en santuarios ubicados en Sonora pero próximos a la frontera -como en las montañas de Teras, uno de los refugios favoritos de Gerónimo y su banda-, o en las estribaciones de la Sierra Madre Occidental, entre los estados de Sonora y Chihuahua, y luego tornaban a atacar asentamientos de vecinos, en dirección sur norte para cruzar su botín a Estados Unidos. La refriega de Teopar-conocida en los anales diplomáticos como el incidente Crawford- confirmó esta práctica el 11 de enero de 1886. Teopar era un sitio inexpugnable, en el distrito de Sahuaripa, a más de $300 \mathrm{~km}$ en línea recta de la frontera México-Estados Unidos -en la misma latitud del puerto de Guaymas-, en una alta serranía llamada por los vecinos "El Espinazo del Diablo”, entre los ríos Aros y Sátachi, afluentes del Yaqui. ${ }^{19}$

\footnotetext{
18 West, Sonora, pp. 1-15 y 70-75.

19 Para sitios que sirven de refugio y base para lanzar ataques y depredar, SweEney, From Cochise to Geronimo, pp. 242-243 y 249; para la marcha al Espinazo del Diablo en enero de 1883, donde los chiricahuas al mando de Juh son sorprendidos el 24 de enero por dos columnas de voluntarios de Temosáchic, Chihuahua, integradas en su mayoría por tarahumaras fogueados en estas campañas, y para la desbandada de los chiricahuas
} 
RASGOS GENERALES DEL CONFLICTO APACHES-VECINOS

El 20 de julio de 1871, a las nueve de la mañana, unos vecinos de la congregación de la Estancia, municipio de Aconchi, fueron atacados por un número aproximado de diez apaches que sorprendió a los lugareños en sus labores. El saldo fue de cinco personas muertas, entre ellos, un joven de 16 años, la madre de éste y otro joven de 12 años de edad que les hacía compañía, además de un herido de flecha. ${ }^{20}$

Algunos más escaparon, no sin defenderse lanzando piedras a los apaches. Algunos vecinos salieron de manera improvisada a perseguirlos, pero al alcanzar a los apaches a un cuarto de legua del ataque, el vecino Remigio Espinoza recibió un balazo y quedó herido de muerte. El resto de los perseguidores se desmoralizó. Al poco tiempo se les unieron otros vecinos que llegaron a reforzarlos, sin embargo, el escenario era desalentador, con los apaches guarecidos en la sierra y los vecinos mal armados, por lo que optaron por retirarse con el cadáver de Espinoza. La noticia llegó al presidente municipal, A. Palacio, que se encontraba en ese momento en la congregación afectada, y quien destacó al vecino Jesús Domínguez al mando de una partida de la Guardia Nacional, conformada por 20 hombres. $^{21}$

portando rifles Winchester con cargadores de 16 tiros, pero poco parque, pp. 279-290; para la conjunción de chiricahuas, voluntarios de Chihuahua y una fuerza estadounidense en Teopar, Sweeney, From Cochise to Geronimo, pp. 493-499, y Almada Bay et al. "El papel de los vecinos", pp. 198-206.

20 RIA, AGES, E, $P$, t. 432, Prefectura de Arizpe, Aconchi, 20 de julio de 1871. Tomás Sierra al prefecto de Arizpe.

21 RIA, AGES, E, P , t. 432, Prefectura de Arizpe, Aconchi, 21 de julio de 1871. A. Palacio, presidente municipal de Aconchi, al prefecto de Arizpe. 
Como éste, existen en los ramos Prefecturas e Indígenas, centenares de casos sobre las acciones emprendidas por la población asentada en Sonora durante el siglo xIx, como respuesta a los daños que las incursiones apaches le causaban. El conflicto violento, directo y recurrente provocó que los habitantes de Sonora emprendieran diversas medidas para hacer frente a las incursiones apaches, sobre todo en el periodo sin la presencia continua y eficaz de unidades del ejército nacional; ésta se alcanzó hacia 1885-1886 y coincidió con el despliegue del ejército estadounidense en el territorio de Arizona, que se acrecentó entre 1872 y $1886 .{ }^{22}$

Las medidas aplicadas por los vecinos de los asentamientos de Sonora que identificamos en las fuentes primarias las calificamos en ofensivas y defensivas. ${ }^{23}$ Las medidas ofensivas se caracterizan por enfrentar a los atacantes, como respuesta a su agresión o despojo, para que éstos no queden impunes y no hagan mayores daños a los vecinos ni a sus bienes; realizan las persecuciones de las partidas apaches en un radio circunscrito o en ocasiones de manera coordinada con los vecinos de otros asentamientos, conformando una "autodefensa limitada", que destaca por su corto alcance militar comparada con la empleada en el territorio estadounidense, y que explica la preferencia de las bandas de los

22 Sobre el ejército nacional en Sonora, véase Almada, LorTa, Domínguez y Contreras, "El papel de los vecinos", pp. 197-233. Para las fluctuantes políticas hacia los nómadas independientes por el ejército estadounidense en el territorio de Arizona, véase SHERIdan, Arizona, pp. 66-99.

${ }^{23}$ En el estado de Coahuila, Martha Rodríguez distingue "estrategias defensivas y ofensivas" establecidas por autoridades regionales y locales, “junto con los vecinos”; RodRíGuez, La guerra entre bárbaros y civilizados, p. 59. 
nómadas independientes por atacar porciones del norte de México. Los pobladores de éste enfrentaban el expansionismo estadounidense y a los indios nómadas beligerantes, que percibían entrelazados. ${ }^{24}$

Las medidas defensivas buscan primordialmente proteger a la población del asentamiento atacado o amagado por los apaches, alertándola de un ataque inminente, con el fin de que se guareciera en el pueblo, abandonando de inmediato la faena que la dispersaba en los alrededores.

Las formas de responder a las hostilidades de los chiricahuas -la rama de los atapascanos que irradiaba del sur del río Gila hasta la Sierra Madre Occidental, en colindancia con el valle de Sahuaripa-, desde el punto de vista bélico, comprenden un abanico de medidas en las que los vecinos tienen una activa participación. La gama va desde el vecino que porta un arma de fuego y se integra a la partida que persigue a la incursión apache, hasta el notable acaudalado que aporta recursos y hombres para la guerra.

Las autoridades civiles locales dirigieron las actividades de la Guardia Nacional contra los apaches y las acciones

${ }^{24}$ Francisco Javier Sánchez Moreno ha denominado "autodefensa limitada" al conjunto de prácticas y de disponibilidad de recursos de los vecinos del noreste de México, en especial entre 1835 y 1846 -entre la independencia de Texas y el inicio de la guerra entre México y Estados Unidos, lapso durante el cual la defensa de la frontera recae en sus pobladores-, en contraste con Texas, que en su periodo independiente y luego como parte de Estados Unidos contaba con compañías de voluntarios bien armados y unidades de militares profesionales. Los comanches y otros pueblos de las planicies optaron por depredar los desguarnecidos ranchos mexicanos antes que los ubicados en Estados Unidos, al parecer por la capacidad de represalia del ejército y vecinos de este país; SÁnchez Moreno, "Apolinario Moreno”, pp. 86-91. 
para resguardar de los ataques a las familias de los vecinos, mientras que desde el Poder Ejecutivo estatal se expedían decretos y circulares que promovían la participación de los ciudadanos armados contra los apaches, ofreciendo retribuir por el ganado represado y las cabelleras de guerreros apaches muertos.

En la amplia gama de una guerra fluctuante -que alcanzó por periodos el paroxismo del exterminio en las proclamas y en los hechos- y de treguas precarias, se registró una interacción que modificó los usos y costumbres de ambas partes.

Para el caso de la población de Sonora se puede hablar de una "apachización” 25 al adoptar armas, tácticas y estrategias adecuadas al terreno local, como atacar por sorpresa gracias al conocimiento de los accidentes del terreno y desplegar una guerra de guerrillas -semejante al modo de combatir "evasivo" de los chiricahuas, de pegar y correr, "mediante escaramuzas y disparando ocultos sin ofrecer un blanco

${ }^{25}$ La participación de los indígenas aliados fue decisiva. Desde la llegada de los misioneros jesuitas a fines del siglo xvir, los llamados ópatas participaron como combatientes auxiliares en la defensa de las misiones contra las incursiones de bandas nómadas, en la región conocida como la Opatería. En la década de 1780 se crearon tres presidios con oficiales y tropa nativos, dos con ópatas y uno con pimas; éstos eran llamados "pápagos" y hoy corresponderían a los tohono o'odham; véase Jacoby, Shadows at Dawn, pp. 12-14. Los ópatas y pimas mostraron que sus tácticas para repeler ataques de apaches y seris eran más eficaces que las de los soldados españoles ubicados en los presidios, al grado que "se puede afirmar que el dominio y defensa de la provincia de Sonora desde un principio estuvieron sujetos a la dependencia de los indios". Borrero SiLva y VeLarDE CADENA, "Las compañías de ópatas", pp. 95-114. Así, la difusión entre los vecinos y los efectivos presidiales del modo de pelear como los indios contra los nómadas beligerantes ocurrió desde la época colonial; Alonso, Thread of Blood, pp. 26-32. 
fijo"--, ${ }^{26}$ al lanzar unidades multiétnicas -integradas por blancos, mestizos, mulatos e indios auxiliares-, que "todo lo obtenían del terreno y sobre la marcha", ${ }^{27}$ con autonomía para elegir la táctica de combate y el radio de acción -incluso para elegir a sus jefes inmediatos-, dejando de lado disciplinas militares convencionales, transplantadas de Europa, de los ejércitos regulares, como avanzar en formación de combate. ${ }^{28}$

Habría que considerar si la sustracción de bienes de campo eventualmente se institucionalizó ${ }^{29}$ como una práctica retributiva, alentada por una laxa práctica de la saca -la proporción del botín quitado a los apaches que correspondía a los vecinos que lo habían disputado- o disimulada por el abigeato, hasta tornarse un complemento de la economía campesina, en el marco de una violencia endémica en el campo. Cristalizando así una modalidad más en la que "la violencia y el homicidio interracial como un todo están inextricablemente ligados al comercio." ${ }^{30}$ Entre los atapascanos se difundió el uso de las armas de fuego, del caballo, las riendas, la silla de montar y los estribos, que les

${ }^{26}$ El entrecomillado está tomado de GARcía, “Bárbaros”, pp. 188-189 y 192; para mediados del siglo xix, en el noreste de México, se observa una "indianización" de la guerra contra los "bárbaros"; había que "combatir como los indios"; véase Sánchez Moreno, "La indianización”, pp. 67-70.

27 García, “Bárbaros”, p. 193.

28 Alonso, Thread of Blood, pp. 30-32; y SÁnchez Moreno, "La indianización", p. 69.

${ }^{29}$ White, The Middle Ground, p. 76.

30 White, The Middle Ground, p. 75. 
permitieron arrojar lanzas o flechas o disparar apuntando con tino al mismo tiempo que cabalgaban. ${ }^{31}$

Luego de la guerra de Texas -de octubre de 1835 a abril de 1836-, la dinámica del conflicto está influida por factores exógenos, como el expansionismo territorial estadounidense, la demanda de ganado vacuno para el mercado urbano de Estados Unidos y la circulación de armas modernas entre los nómadas provistas por comerciantes asentados en Estados Unidos a cambio del ganado sustraído de México. Estos dos últimos factores se incrementaron al finalizar la guerra civil estadounidense, en $1865 .^{32}$

En el espacio correspondiente al estado de Sonora actual, la necesidad de autodefensa de los asentamientos para hacer frente a un enemigo externo común condujo a la integración de la Guardia Nacional por vecinos e indios aliados, como efecto de una percepción colectiva de asedio continuo, aunque la violencia fuera intermitente.

A partir de 1857, el gobernador Ignacio Pesqueira ofreció seguridad a la población del estado. Sin embargo, su gobierno no contaba con recursos para ese propósito, por lo que presentó la respuesta al conflicto con los apaches como una responsabilidad de todos los ciudadanos, los cuales, de ser necesario, debían erogar de sus propios medios: ${ }^{33}$

31 JAсову, Shadows at Dawn, p. 161.

32 Sмith, "Indians", pp. 43-44.

33 En noviembre de 1858 el prefecto de Arizpe reporta que "Se han venido [por traído] al Señor Inspector algunas reces y un macho alazán de Aconchi, pertenecientes al donativo de Campaña contra los Apaches”, RIA, AGES, E, P, t. 311, Renta de papel sellado \#2, Huépac, 10 de noviembre de 1858. Circular del prefecto de Arizpe. 
[... se ha enterado el C. Gobernador de las ocurrencias de apaches comunicadas por el C. Presidente municipal de Ymuris y ha visto con profundo desagrado que no se les haya perseguido por falta de recursos, supuesto que está V. como gefe del Distrito en la obligacion de remover todos los obstaculos que se presenten, para garantizar las vidas é intereses de esos habitantes y ellos en el deber de prestar sus auxilios cuando sean necesarios, obligando a esos C.C. si fuere presiso á verificar la persecucion de los barbaros que hostilizan esos pueblos. ${ }^{34}$

Con este fin se crearon juntas de auxilio, destinadas a recaudar donativos para equipar a la Guardia Nacional contra los apaches. ${ }^{35}$

\section{MilitarizaCión DE LA VIDA COTIDIANA}

Para los habitantes del norte de Sonora, el espacio de sociabilidad, entendido como el ámbito donde se desarrolla la vida cotidiana, ${ }^{36}$ era parte de la zona de enfrentamiento con bandas chiricahuas. De ahí que los vecinos se vieran afectados por las incursiones de éstos en las zonas aledañas a sus

${ }^{34}$ RIA, AGES, $E$, $P$, t. 458, Prefectura del Distrito de Magdalena, noviembre de 1874, Ures, 19 de noviembre de 1874. Secretario de gobierno al prefecto de Magdalena.

35 LeÓn, El conflicto apache, pp. 130-132.

${ }^{36}$ El espacio de sociabilidad es el ámbito cotidiano donde tiene lugar la vida de un individuo e interactúa con otras personas o grupos. En él se distinguen el espacio doméstico, que comprende los lugares compartidos por las personas que habitan una casa, y los espacios públicos, aquellos lugares donde coinciden y se relacionan los habitantes de un asentamiento, como las orillas de los ríos y arroyos, donde las mujeres lavan la ropa y se abastecen de agua, caminos, calles, plazas, templos y campos de labor; Gonzalbo, Vivir en Nueva España, pp. 163-165. 
hogares, como en los caminos y campos de labor, incluso dentro de sus pueblos y casas. En este conflicto no se hacía distinción entre combatientes y no combatientes, por lo que cualquier vecino, sin importar su edad, origen étnico o género, estaba expuesto a perder sus bienes, ser tomado cautivo o muerto por los apaches. Y los vecinos hacían lo mismo con la población apache cuando atacaban sus rancherías o en combate.

En el caso de las incursiones chiricahuas en Sonora, se ha identificado que las partidas irrumpían en los vecindarios, por lo regular, durante el día, aprovechando que los vecinos estaban dispersos por el pueblo y sus alrededores, ocupados en sus trabajos cotidianos, descuidando las labores de vigilancia y defensa, como se registró en el fuerte de Fronteras en 1859:

A las diez de la mañana de este fueron asaltados los vecinos que se encontraban en las inmediaciones de este fuerte en sus trabajos de sus labores por los indios barbaros en numero de mas de sesenta quienes tubieron la audacia y osadia de internarse hasta las primeras casas de esta corta población, de que resultó el haber cojido prisionero al vecino José Nicolas Sillas que estaba en sus regadios, dos niños mas[,] uno del armero de este [del fuerte] y el otro del soldado Rafael Villa del mismo. ${ }^{37}$

Ante lo imprevisto y perjudicial de estos ataques, las autoridades locales y los vecinos adoptaron medidas ofensivas para contraatacar a las incursiones apaches y locali-

37 RIA, AGES, $E, P$, t. 341, Prefectura de Arizpe, correspondencia de enero a diciembre, Prefectura del Distrito de Arizpe, mayo de 1859, Huépac, 3 de mayo de 1859. Juez local del fuerte militar de Fronteras al Prefecto de Arizpe. 
zar sus rancherías, que usaban como bases de ataque, en las sierras colindantes a los asentamientos.

Las muertes y pérdidas materiales ocasionadas por las incursiones chiricahuas a los asentamientos, sumadas a la poca ayuda de los gobiernos nacional y estatal para contenerlas, estimularon acciones de autodefensa por parte de los vecinos, lo que se tradujo en una militarización de la vida cotidiana.

La violencia y los daños producidos por las incursiones apaches provocaron en los habitantes de la frontera la percepción de estar asediados. En 1847 el párroco de Cieneguilla, en el distrito de Altar, Francisco Xavier Vázquez, atribuyó a las incursiones apaches el entorpecimiento para prestar auxilios espirituales en la frontera y para el funcionamiento de la escuela de primeras letras, diciendo que para transitar por las 100 leguas que cubren su parroquia "Treinta d. Escolta q. le acompañan, no le aseguran el escape de la vida, por q. suele presentarse el Enemigo en reunión d. doscientos, á quinientos equipados y armados d. Rifles q. damos por cierto ser subministrados por los Anglos" ${ }^{38}$

Años después, en 1854, el prefecto de Ures señaló en un informe: "Certifico en cuanto puedo, debo y el derecho me permite: que es muy público y notorio el hallarme invadido por los bárbaros apaches, todos los tránsitos de los pueblos de este desgraciado departamento, en cuyos caminos han sido inmoladas innumerables víctimas de la barbarie de dicho enemigo, [...]";39 del mismo modo, al informar sobre

38 AHAH, E, $A$ y G S10, exp. 3, leg. 10. Cieneguilla, 23 de abril de 1847, Párroco Francisco Xavier Vázquez al gobernador de la mitra en Culiacán, Pedro Loza. Para el cargo de Loza, véase Almada, Diccionario, p. 384. 39 RIA, AGES, $E$, $P$, t. 269, s. e., f. 214:2, 24 de marzo de 1854. Fernando 
las novedades ocurridas en Bacoachi en 1855, se afirma: "Ya nos comen vivos los Apachis, no hay día que no los vean o corten guellas los que van a la leña que los que vienen de Fronteras". ${ }^{40}$

Las consecuencias de las incursiones de los apaches, en especial las muertes de vecinos, producían en la población lo que el prefecto de Moctezuma llamó "horror pánico". ${ }^{41}$ Ante el riesgo de ser atacados o muertos por apaches en los caminos y orillas de los asentamientos, los vecinos temían realizar sus actividades cotidianas; en ocasiones se negaban a salir de los pueblos a las tierras de cultivo situadas en las inmediaciones, ${ }^{42}$ lo que obstaculizaba la economía de

[ilegible], Comandante de [ilegible] retirado y prefecto del partido de Ures, capital del departamento de Sonora.

${ }^{40}$ RIA, AGES, $E, P$, t. 283, Bacoachi, 31 de mayo de 1855, Manuel del Río a Rafael Corella.

41 "Esta escaramusa fue presenciada muy de cerca por mi y no me queda la menor duda que estos habitantes estan agarrados de un horror panico que sin duda no tardará mucho en que los bárbaros no necesiten armas para matarnos, pues como he dicho pesencié la escaramusa muy de cerca y me consta que 7 hombres bien armados y posecionados de una buena casa pasando los indios á corta distancia en pelotón y no hubo quien les tirara un solo tiro. Mas al sur se encontraban otros 8 hombres tambien armados y tampoco les tiraron[,] corrieron, pero estos se quiera [sic, por siquiera] fueron sorprendidos [...]". RIA, AGES, $E$, $P$, t. 434, 1871, Prefectura de Moctezuma, Moctezuma, 19 de diciembre de 1871, J. Aragón, prefecto de Moctezuma, al secretario de Estado.

42 En 1878 el prefecto de Sahuaripa, M. Cuen, informó al secretario de Estado: “[...]. Este Distrito se encuentra invadido por los bárbaros á tal grado que ya sus habitantes no quieren salir de las poblaciones á hacer ningun negocio, si el C. Sub Ynspector no toma medidas de que se les haga una tenas persecucion por fuerzas competentes[,] en breve estos habitantes abandonarán sus pueblos para vuscar donde garantizar siquiera su vida”. RIA, AGES, $E, P$, t. 465bis, Prefectura del Distrito de 
autosuficiencia alimentaria de la que dependían los asentamientos pequeños.

Este temor no era infundado, una parte significativa de las muertes de vecinos atribuidas a ataques apaches se registró en las afueras de las poblaciones, por ejemplo, en las labores de cultivo y en las tierras de pastoreo, contribuyendo a que ocurrieran 30 despuebles totales de ranchos y pueblos asediados por los chiricahuas. ${ }^{43}$ Entre 1851 y 1870 la población de la entidad federativa mexicana de Sonora registró la caída más pronunciada en el siglo xIx, de acuerdo con las estadísticas disponibles, atribuyéndose a los apaches una porción del declive demográfico, sobre todo de las muertes y los desaparecidos, considerados probables cautivos de los nómadas. El declive de la población también estuvo influido por las migraciones a la Alta California por la fiebre del oro a partir de 1848 y a Arizona durante el resto del siglo xIX, así como por las muertes debidas a la epidemia de cólera en 1850-1851.44

Los viajeros corrían grandes riesgos, ya que se exponían a ser emboscados al transitar de un asentamiento a otro. Así ocurrió con la familia de Francisco Vazques Bustamante en abril de 1870, la cual fue atacada por aproximadamente 40 apaches en el camino entre Moctezuma y Cumpas, muriendo Vazques, su esposa y una hija de 5 años, quienes habían salido por un médico para tratar a la esposa de Vazques. ${ }^{45}$ Las

Sahuaripa, octubre de 1878, Sahuaripa, 15 de marzo de 1878, M. Cuen, Prefecto de Sahuaripa, al secretario de Estado.

43 Almada Bay, Lorta, Contreras y Reyes Gutiérrez, "Casos de despueble".

${ }^{44}$ Almada Bay, Lorta, Contreras y Reyes Gutiérrez, "Casos de despueble".

${ }^{45}$ RIA, AGES, E, $P$, t. 427, Moctezuma, Moctezuma, 25 de abril de 1870. 
fuentes muestran que en ocasiones los viajeros hicieron testamento antes de realizar un viaje, como el minero alemán Guillermo Schuster, "que teniendo que hacer un viaje al Distrito de Sahuaripa á atender sus negocios mineros y temiendo que vaya a sucederle una desgracia”, redactó el suyo como medida de precaución. ${ }^{46}$

La inseguridad de los caminos y la falta de circulante propiciaron que el comercio no fuera suficiente para que los habitantes obtuvieran por este medio los bienes necesarios para su subsistencia. ${ }^{47}$ Para proveer las necesidades cotidianas se practicaba una economía de autosuficiencia alimentaria en la que las familias funcionaban como una unidad económica que consumía lo que producía, y en la que cada uno de sus miembros, incluidos los niños, aportaba su trabajo al sostenimiento del grupo; en caso de contar con excedentes, éstos se intercambiaban.

Las familias obtenían la parte básica de su alimentación mediante la labranza de la tierra. Esta era la ocupación principal de $75 \%$ de los hombres que vivían en asentamientos rurales entre 1840 y $1853 . .^{48}$ Las fuentes primarias de la base de datos muestran que toda la familia colaboraba en esta tarea, donde sus miembros corrían igual peligro en caso de un ataque de apaches. ${ }^{49}$

46 Testamentos de Sonora, 1786-1910, http://www.colson.edu.mx:8080/ testamentos/principal.aspx. Guillermo Schuster, Hermosillo, 1888.

47 Para el impacto negativo de la carencia de circulante en la región a fines del periodo colonial, véase Torre Curiel, "Comerciantes", pp. 595-656. ${ }^{48}$ Shelton, For Tranquility and Order, p. 14.

49 Tomemos este ejemplo: “Tengo el desagrado de comunicar á U. que á las once de la mañana del dia 20 del corriente una pequeña partida de apaches desembocando por una de las cañadas que salen debajo de la Comisaria de la 'Estancia' salió al valle y cebó su saña en algunas familias de 
Para complementar los productos obtenidos por medio de la labranza, los hombres combinaban las actividades de siembra con las de gambusino, arriero, sirviente en alguna hacienda o criador de ganado; por su parte, las mujeres se ocupaban de las labores del hogar, el cuidado del ganado y del huerto, la recolección de frutas silvestres y palma, y el manejo del rancho, la labor de siembra o el negocio familiar en la ausencia temporal o permanente de su pareja o junto a ella. Además, compartían el trabajo con los hombres en los campamentos mineros o en las tierras de cultivo, combinando estas actividades con la crianza y el cuidado de los hijos. Los niños y jóvenes ayudaban a vigilar el ganado, a llevar encargos o a recolectar frutas silvestres, mientras que los adultos trabajaban en las haciendas y ranchos o en la "labor", trozo de tierra en posesión de la familia. ${ }^{50}$

Parte del excedente de esta economía de autosuficiencia alimentaria se destinaba a la Guardia Nacional y a los fuertes militares de la frontera, ${ }^{51}$ pues la constante escasez de recursos públicos obligaba a los vecinos a abastecer de víveres y otros avíos a estas fuerzas, por medio de donativos

dicha población que encontró ocupados en sus tareas de labranza. Cinco fueron las victimas sacrificadas por el enemigo y cuyos nombres no consigno, por no recibir el parte detallado de tamaña catástrofe [...]”. RIA, AGES, $E, P$, t. 432, Prefectura de Arizpe, Aconchi, 21 de julio de 1871, A. Palacio, prefecto de Arizpe, al secretario de Estado.

${ }^{50}$ ReYes, "Estrategias", pp. 71-77.

51 “[...] Quedo impuesto asi mismo de las medidas tomadas por VE para que la citada junta directiva libre sus ordenes a la mayor del Distrito de Arizpe a fin de que [de] los productos de los donativos de aquellos pueblos se me proporcionen los viveres necesarios al abastecimiento de los Fuertes militares de la Frontera.” RIA, AGES, E, $P$, t. 328, Ures, 27 de agosto de 1858, J. Juan Elías, prefecto de Ures, al gobernador. 
voluntarios, juntas de auxilios y el fondo de Guardia Nacional al que ingresaban las cuotas que pagaban aquellos que querían quedar exceptuados de participar en esta fuerza. ${ }^{52}$ Así, en 1858, la junta de auxilios de Rayón remitió a la capital del estado, Ures, 110 fanegas de pinol, además de reses, jabón y panocha ${ }^{53}$ un mes después se recogieron donativos para las campañas contra los apaches, que consistieron en la sal que se donó en Aconchi, jabón, cigarros y caballos del distrito de Arizpe ${ }^{54}$ y pinol de Rayón. ${ }^{55}$

En ocasiones, debido a la escasez de fondos, las fuerzas que perseguían a los apaches se abastecían de alimentos sobre la marcha, a expensas de los bienes de los particulares. En 1858, Ramón Romo, capitán de una partida de Guardia Nacional de Guadalupe, reportó que durante una persecución sus soldados "mataron por necesidad un becerro de año a dos, del [rancho] tecolote [,] orejano de fierro, y un burro de dos a tres, del rancho viejo [...]". ${ }^{56}$ En 1858 el prefecto de Sahuaripa envió una partida de Guardia Nacional de Pónida a apostarse en el pueblo de Tarachi. Sobre el funcionamiento y sostenimiento de esta fuerza informó:

52 CIS, BELY, r. 89, A. Parroquial, Banámichi, 7 de abril de 1849. Las autoridades y vecindario del pueblo de Banámichi al gobernador.

${ }^{53}$ RIA, AGES, $E, P$, t. 330, Libro de Borradores en minuta, Ures, 12 de octubre de 1858. Presidente de la Junta de Auxilios de Rayón.

${ }^{54}$ RIA, AGES, $E, P$, t. 330, Libro de borradores 1858, Fronteras, 13 de noviembre de 1858. Al prefecto del distrito de Arizpe.

${ }_{55}$ RIA, AGES, $E, P$, t. 328, 1858. Correspondencia de la Prefectura de Ures del mes de noviembre, Ures, 8 de noviembre de 1858. José E. Moreno, prefecto de Ures, al inspector y comandante de la Frontera.

${ }^{56}$ RIA, AGES, $E$, $P$, t. 329, 1858. Comandantes de partidas vueltas núm. 6, Guadalupe, 29 de octubre de 1858. Ramón Romo, capitán de la Guardia Nacional de Guadalupe. 
En virtud de las continuas incursiones que hacen a este Distrito los barvaros apaches, tan luego que tomé posición del empleo de Prefecto Interino, que el E.S. Governador tubo a bien conferirme, traté de asegurar en cuanto era posible la tranquilidad de estos habitantes y al efecto, por los informes y otros antecedentes que recibí de las personas de mas conocimiento, dispuse alistar la marcha de 20 hombres de la G. Nacional de Yndijenas de Ponida al Pueblo de Tarachi, al mando del Teniente Gral. Emiliano Valencia: ban a cumplirse cuatro meses que dicha fuerza se halla de destacamento, y en activo serbicio en aquel Pueblo; dando los mejores resultados que podian decearse, pues los barbaros se han retirado de aquellos rumbos [...]. Esta fuerza se ha sostenido solamente con el pequeño ausilio de un bastimento de pinol, y alguna vez de carne facilitado voluntariamente por el vecindario de dicho Pueblo; y unicamente en la espedicion de mi vicita a todo el Distrito que acabo de practicar, y en la que me acompañaron en clase de escolta recibieron a (ilegible) del tiempo de su serbicio un mes de sueldo de Sargento á bajo [...]. ${ }^{57}$

De igual modo, el capitán de infantería de la Guardia Nacional de Sahuaripa, Concepción Alegría, al comunicar en abril de 1873 el resultado de la persecución emprendida sobre una partida de apaches, anotó que durante la operación carecían de alimentos y tuvieron que ser auxiliados por particulares: "Amanecimos sin ningunos viveres habiendo cenado la noche anterior quelites tatemados; luego emprendí la

57 RIA, AGES, E, P , t. 327, Prefectura de Sahuaripa, 1858, núm.11, Sahuaripa, Sahuaripa, 10 de octubre de 1858. Francisco Manzanero, prefecto del distrito de Sahuaripa, a José Juan Elías, teniente coronel e inspector de la Frontera. 
marcha y vine á dormir al rancho de Chipájora, en donde los vaqueros facilitaron á la fuerza una cena limitada [...]" ${ }^{58}$

Por otro lado, es probable que la saca otorgada por los propietarios a la partida que entregara los robos represados a los apaches se volviera un complemento para la economía campesina, pues de esta manera los vecinos que exponían su vida y no contaban con un hato de ganado podían hacerse de bienes de campo que acrecentaran su patrimonio; de otra manera difícilmente podrían obtenerlos. ${ }^{59}$

Los recursos de los particulares no sólo servían para sostener a la Guardia Nacional, sino también para auxiliar a las familias de los vecinos muertos en los enfrentamientos con los chiricahuas. En enero de 1860, vecinos del distrito de Moctezuma proporcionaron un auxilio voluntario para las viudas y huérfanos de los nacionales de Tepache "que murieron en la cuesta de apie en guerra con los Apaches", juntando un total de 42.25 pesos. $^{60}$

En diciembre de 1868 se expidió un reglamento para establecer colonias militares en la frontera norte del país, con el fin de "defender las fronteras de la República de las incursiones de los indios bárbaros" ${ }^{61}$ Este reglamento estipuló que los colonos interesados en marchar a la frontera recibirían los avíos necesarios para que se establecieran junto con sus familias. Los avíos consistían en materiales de

${ }^{58}$ RIA, AGES, $E, P$, t. 448, Prefectura de Sahuaripa, Sahuaripa, 11 de abril de 1873, Concepción Alegría, capitán de infantería de Sahuaripa.

59 Almada Bay, "La saca”, pp. 563-590.

60 RIA, AGES, $E, P$, t. 356, Prefectura de Moctezuma, Moctezuma, 10 de enero de 1860, J. Aragón, prefecto de Moctezuma.

${ }^{61}$ Reglamento para el establecimiento de las Colonias Militares en la frontera del norte, 1869. 
construcción, un lote de siembra y herramientas de labran$\mathrm{za}$, además de un sueldo mensual, ${ }^{62}$ a cambio estaban obligados a salir en persecución de los nómadas cada vez que se presentara una incursión y a observar la disciplina militar. ${ }^{63}$

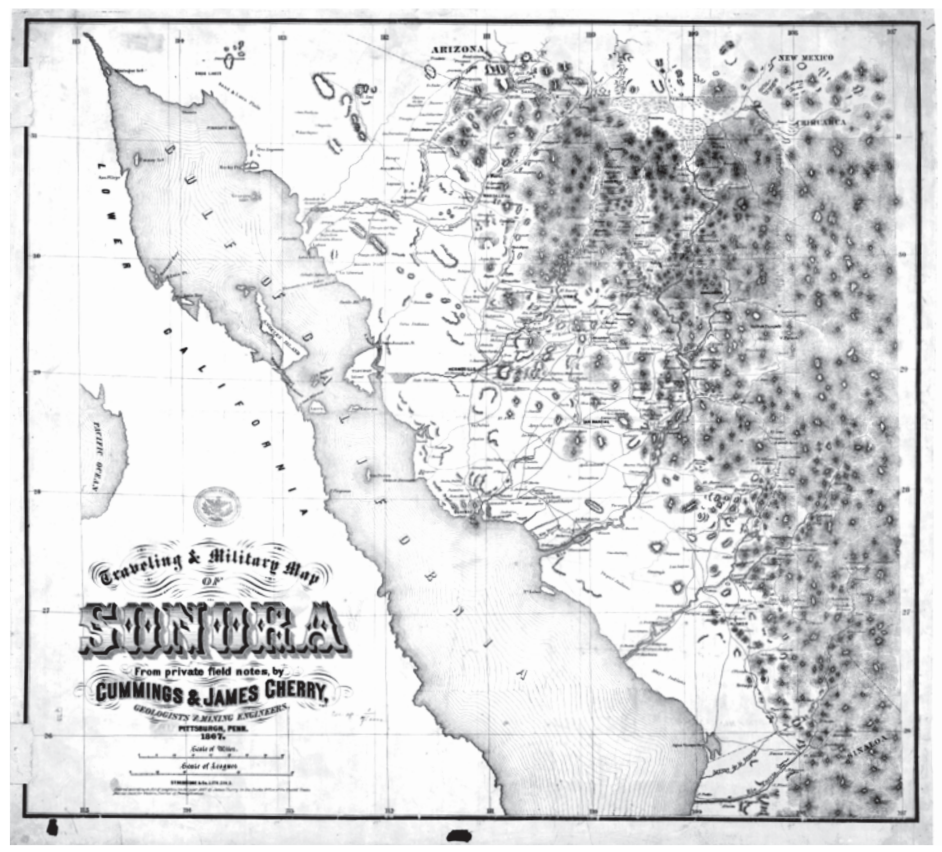

Cummings y James Cherry, Traveling and Military Map of Sonora, Pittsburgh, Pensilvania. 1867. Mapoteca Manuel Orozco y Berra, núm. clasificador 10705-CGE-7215-A http://w2.siap.sagarpa.gob.mx/mapoteca/

${ }^{62}$ Artículo 4ํㅜ Reglamento para el establecimiento de las Colonias Militares en la frontera del norte, 1869.

${ }_{63}$ Título IV, Reglamento para el establecimiento de las Colonias Militares en la frontera del norte, 1869. 
En Sonora se crearían siete colonias militares, de las que se tiene constancia del funcionamiento de cinco: Bavispe, Bacoachi, San Ignacio, Santa Cruz y Fronteras, las dos últimas desde $1849 ;{ }^{64}$ sin embargo, su población no estaba compuesta por individuos enganchados en las oficinas establecidas para ese fin, como señala el reglamento de $1869,{ }^{65}$ sino por habitantes de los distritos fronterizos que se trasladaron con sus familias atraídos por las tierras de labranza ofrecidas o por miembros de la Guardia Nacional a los que se les impuso este servicio. Aun así, la fuerza era escasa y sus recursos insuficientes, por lo que dependían del apoyo de los asentamientos próximos para realizar su labor, ${ }^{66}$ de modo que quienes poblaron esas colonias militares eran vecinos que de antemano desempeñaban actividades de autodefensa. El reglamento de 1868 retomó el expedido por decreto del presidente José Joaquín de Herrera, el 19 de julio de $1848 .{ }^{67}$

${ }^{64}$ RIA, AGES, E, $P$, t. 284, Prefectura de Arizpe, 1855, Expediente que contiene correspondencia sobre distintos asuntos con la Prefectura del Distrito de Arizpe en todo el año expresado, Bacoachi, 1ำ de enero de 1855, vecinos de Bacoachi al prefecto del distrito.

65 Título III. Enganches y filiaciones, artículos $1^{\circ}, 2^{\circ}, 3^{\circ}$ y $4^{\circ}$. Reglamento para el establecimiento de las Colonias Militares en la frontera del norte. 1869 .

66 En 1875, Susano Montaño, prefecto de Moctezuma, al secretario de Estado: "Es una verdad incontestable que por bien gobernadas que sean las colonias militares que ha establecido en nuestra frontera el Gobierno Gral. no sirvan para prestar la seguridad en sus personas é intereses de nuestro avatido Sonora, pues siendo tan estenso el terreno de la frontera no se puede impedir que los indios hagan sus campañas al centro de estos pueblos [...]”. RIA, AGES, E, P, t. 365, 1875, Moctezuma, Correspondencia de enero a diciembre, Prefectura del Distrito de Moctezuma, octubre de 1875, Moctezuma, 5 de octubre de 1875.

${ }^{67}$ Colonias Militares. Se compone de 31 artículos en cuatro fojas, más dos mapas, dos cuadros y el plano del edificio de una colonia. 
La guerra impuso un orden; ${ }^{68}$ desde la época colonial los habitantes de la frontera estuvieron familiarizados con las medidas ofensivas y defensivas realizadas por las compañías de soldados presidiales e indígenas auxiliares asentadas en la región, que originalmente eran las encargadas de defender la frontera de las incursiones de los nómadas.

$\mathrm{Al}$ inicio de la época independiente, en 1823, se expidió un reglamento de milicias cívicas para formar unidades locales de ciudadanos armados que defendieran el territorio nacional de amenazas externas. ${ }^{69} \mathrm{Su}$ conformación era multiétnica, al abolir las distinciones estamentales. ${ }^{70}$ Se autorizó el uso de estas milicias como fuerzas auxiliares de las tropas regulares y presidiales encargadas de contener las incursiones apaches. ${ }^{71}$ Las milicias cívicas subsistieron como fuerza regular hasta 1836, sin embargo, la decadencia en paralelo del sistema presidial obligó a los vecinos a la autodefensa. ${ }^{72}$

68 Rodríguez, La guerra entre bárbaros y civilizados, p. 61.

69 Chust y Serrano Ortega, “Milicia y revolución”, p. 97. Véase también Reglamento de milicias cívicas. http://www.biblioteca.tv/artman2/ publish/1823_122/Decreto_Adicional_al_reglamento_de_milicia_civica. shtml

70 Gayol, “Las milicias nacionales”, pp. 467-471.

71 La ley de 6 de junio de 1830 autorizó la organización de las milicias cívicas en el Estado de Occidente. De forma simultánea “se abrió una suscripción voluntaria” para que los particulares erogaran recursos destinados al entrenamiento y organización de estas fuerzas. Almada, Diccionario, p. 411.

72 En 1834, el gobernador Manuel Escalante y Arvizu publicó un manifiesto que exhorta a todos los habitantes del estado a salir a combatir a los apaches. Este documento menciona la "voluntad de varios pueblos por medio de algunas personas para reunirse una fuerza muy respetable é interesante al campo que ocupa el enemigo á castigar la osadía con que el lo há hecho al territorio del Estado”, añadiéndose que “esas personas de un modo seguro y positivo han entregado mucha parte de sus 
La organización de la Guardia Nacional se autorizó en el país el 15 de julio de 1848, y dos años después funcionaba en todos los municipios de Sonora. ${ }^{73}$ De acuerdo con la normatividad, el financiamiento provenía de los ayuntamientos y de la cuota que pagaban los exceptuados, y sus integrantes eran retribuidos con el sueldo correspondiente al tiempo de su servicio y con el botín quitado al enemigo extranjero, el cual se repartía entre las autoridades y los milicianos. ${ }^{74}$

En los distritos fronterizos de Sonora, la Guardia Nacional fue la fuerza que participó con mayor protagonismo en las medidas ofensivas contra los apaches. Así, el contexto de los asentamientos ubicados en los distritos fronterizos de Sonora provocaba que sus habitantes asumieran funciones similares a las descritas en el reglamento para las colonias militares.

Al igual que lo estipulado para los colonos, los vecinos de la frontera de Sonora establecidos con sus familias en una área de conflicto con los nómadas independientes debían combinar las actividades por la subsistencia con las de defensa, ya que como miembros de la Guardia Nacional estaban obligados a participar en las medidas ofensivas que se emprendieran, realizando una autodefensa sosteni$\mathrm{da}$ en su mayor parte por la autosuficiencia alimentaria y por los excedentes en caso de haberlos. ${ }^{75}$ Esto, junto con la

\footnotetext{
intereses á la consecución de la empresa [...]”. CIS, BELY, r. 90, A. Parroquial, Arizpe, 1834, "Manifiesto que el gobernador del estado dirige a los pueblos del mismo, con el interesante objeto de hacer campaña al bárbaro apache".

73 Almada, Diccionario, p. 285.

74 Hernández Chávez, “La Guardia Nacional”, p. 243.

75 Otras fuentes de recursos son los gestionados por el diputado Fernando
} 
exposición de los vecinos a un ataque, estimuló una militarización de la vida cotidiana de los habitantes de esta zona depredada por los chiricahuas.

Además de la Guardia Nacional, las fuentes indican que propietarios, mayordomos, vaqueros, medieros, aparceros, parientes, sirvientes, peones y arrimados hacían causa común en la autodefensa y salían a represar robos del ganado en calidad de voluntarios, amalgama calificada por estudio$\operatorname{sos}^{76}$ como "ejércitos particulares de los propietarios", integrados por gentes que vivían en "zonas expuestas a ataques de los nómadas o de bandidos [...], una situación de hecho que nacía de la falta de gobierno en un país tan vasto", formando una cuadrilla multiétnica integrada por criollos, mestizos, mulatos e indios aliados o asimilados.

Así ocurrió en Altar, en julio de 1857, cuando al primer aviso de una incursión de apaches al rancho de Los Pozos, Francisco Escalante, su hijo Braulio y tres de sus vaqueros

Cubillas ante la federación, así como las contribuciones extraordinarias y el pago de exentos de la Guardia Nacional; Trejo Contreras, Redes, p. 226.

76 Chevalier, "Survivances”, p. 6. Este autor tiene en mente los latifundios del norte central y oriental de México. En Sonora no se registraron concentraciones de tierras semejantes a la de la familia Sánchez Navarro en Coahuila o la de los Terrazas en Chihuahua, por lo que una nómina como la descrita antes quizá sólo entró en acción para rechazar la expedición de filibusteros mandada por Henry A. Crabb en abril de 1857, de acuerdo con los anales locales, formada por guardias nacionales de los pueblos de Altar, Pitiquito, Cucurpe, Opodepe y Tuape, dragones presidiales de Bavispe, un piquete de soldados nacionales, auxiliares de caballería de Altar, vecinos de Caborca, y un cañón, armas, municiones y hombres aportados por hacendados de la región. Mestizos, criollos, yaquis, pápagos y ópatas batieron a los filibusteros; en Villa, Compendio, pp. 272-292. 
salieron en auxilio de dicha población, ${ }^{77}$ del mismo modo, diez vaqueros del rancho de Chipájora persiguieron un robo junto a la Guardia Nacional de Sahuaripa en junio de $1871 .^{78}$

La particularidad de los voluntarios era desempeñar labores de defensa sin estar enlistados en la Guardia Nacional por ser sirvientes, por ejemplo; se sumaban para realizar alguna medida ofensiva en contra de una incursión de apaches, o como auxiliares de una partida de la Guardia Nacional destacada para tal efecto o integrados a ella. ${ }^{79}$

Esta autodefensa no estaba exenta de dificultades. La escasez de población para realizar la defensa de los pueblos se agudizaba por el envío a los fuertes militares de hombres

77 RIA, AGES, $E, P$, t. 301, 1857, correspondencia con la Prefectura de Altar, marzo a diciembre, julio de 1857, Altar, 28 de julio de 1857. Correspondencia particular. Francisco U. Escalante a José M. Redondo, prefecto de Altar.

78 "El dia 20 del corriente regresó la partida de nacionales que al mando del C. Teniente Francisco Tequida salió en persecucion de los apaches que carnearon reses y levantaron robo del punto nombrado el 'Daguari' del rancho de Chipajora, de que di cuenta á esa superioridad en oficio fecha 16; cuya partida obrando en combinación con la de diez infantes vaqueros del referido rancho, persiguieron á los enemigos con la mayor actividad, [...].” RIA, AGES, $E, P$, t. 434, 1871, Prefectura de Sahuaripa, Sahuaripa, 23 de junio de 1871. J. N. Cruz, prefecto de Sahuaripa al secretario de Estado.

79 “[...] El 17 del corriente llegué a esta población, y el 18 regresó D. Manuel Villaescusa con los voluntarios de Arizpe y Bacoachi, que habian salido con el objeto de reconocer varios puntos inmediatos donde se creian ranchados algunos indios; $\mathrm{y}$ no habiendo quedado satisfecha esta prefectura del reconocimiento que se hizo, dispuse salir con la misma fuerza, la cual regularicé nombrando mayor de ella a $\mathrm{D}$. Angel José de Tubera, de oficiales D. Manuel Villaescusa, D. Tomas Jacome, D. Sacarias Carrillo, D. Lucas y D. Jose Maria Morales. [...].” RIA, AGES, $E, P$, t. 324, Prefectura del Distrito de Arizpe, febrero de 1858, Bacoachi, 23 de febrero de 1858, Santiago García, prefecto de Arizpe, al gobernador. 
en edad de tomar las armas, como lo expuso el prefecto de Moctezuma José Aragón en abril de 1872:

[...] Con demasiado pesar estoy al ver que por mas que nos esforcemos en castigar á los bárbaros no lo conseguimos por la suma escases de armas y parque; asi como que el pueblo está sin gente por estar 20 y tantos hombres en Fronteras ya va para dos meses, y no los manda [de regreso] el Comandante de la linea Fronteriza siendo que en estos pueblos son tan necesarios, agregandose que después de no haber un soldado, los barbaros se avistan todos los dias por diversos rumbos. [... ${ }^{80}$

Además, durante periodos de estancia prolongada, integrantes de la Guardia Nacional enviados a los fuertes militares se escurrían. Si bien no desertaban formalmente, abandonaban los fuertes militares, lo que era considerado un escándalo y un crimen por las autoridades civiles.$^{81}$ Los fugados regresaban a sus pueblos, argumentando la falta de pago de los sueldos a los que tenían derecho, las malas condiciones del equipo bélico y de los alimentos, ${ }^{82}$ y el desamparo en

${ }^{80}$ RIA, AGES, $E, P$, t. 443, Moctezuma, 23 de abril de 1872. J. Aragón, prefecto de Moctezuma, al secretario de Estado.

${ }^{81}$ RIA, AGES, $E, P$, t. 398, Prefectura de Sahuaripa, Sahuaripa, 17 de mayo de 1867, J. N. Cruz, prefecto de Sahuaripa, al gobernador.

82 “Ayer se han presentado á esta Prefectura nueve Soldados de G. N. del Distrito de los que estan prestando sus servicios en el fuerte militar de Fronteras, los cuales me han manifestado hacia cuatro dias desertaron de aquel fuerte por hambre, pues el rancho que reciben dicen ser un plato de atol de pinol perdido por la mañana y otro por la tarde sin ninguno otro prest [...]". RIA, AGES, $E, P$, t. 341, Prefectura de Arizpe, correspondencia de enero a diciembre, Prefectura de Arizpe, junio de 1859, Huepac, 14 de junio de 1859. Santiago García, prefecto de Arizpe, al gobernador Pesqueira en Mazatlán. 
el que quedaban sus familias en los asentamientos de origen. Ante las acciones de las autoridades civiles por castigar esta conducta, los escabullidos se justificaban. Una representación de fugitivos del servicio prolongado en los fuertes militares, vecinos de Huépac, declaró en 1859 que "de ninguna manera se verá con disimulo por nosotros la aprehencion tan recomendada de los desertores en esta ciudad". ${ }^{83}$

\section{MEDIDAS OFENSIVAS}

Las 12 medidas ofensivas utilizadas por los vecinos como respuesta a las incursiones apaches están identificadas por el nombre tomado literalmente de las fuentes, igual que sus funciones. Su clasificación en ofensivas y defensivas es de los autores. Más adelante explicamos este ejercicio de agrupamiento.

El cuadro presenta por orden de frecuencia las 12 medidas ofensivas. Las diferencias y semejanzas de éstas, así como su complementariedad, se señalan en los siguientes apartados.

\section{Lapersecución}

La medida más frecuente y pronta a una incursión de apaches era la persecución, que tenía como objeto represar el robo, alejar a los apaches del lugar y conocer el rumbo que tomaron. Ésta se ejecutaba en cuanto era posible organizar

${ }_{83}$ RIA, AGES, $E, P$, t. 341, Prefectura de Arizpe, correspondencia de enero a diciembre, Prefectura del Distrito de Arizpe, marzo de 1859, Huepac, 16 de marzo de 1859. Presidente del ayuntamiento de Arizpe al prefecto de distrito. 
Cuadro 1

MEDIDAS OFENSIVAS REPORTADAS POR LAS AUTORIDADES

LOCALES DEL ESTADO DE SONORA EN RESPUESTA

A LAS INCURSIONES APACHES, 1854-1890

\begin{tabular}{lc}
\hline & Número de reportes por medida ofensiva \\
Nombre & Cantidad \\
\hline Persecución & 1713 \\
Campaña & 553 \\
Partidas preparadas & 410 \\
Cortada & 408 \\
Exploradores & 208 \\
Destacamento & 152 \\
Fatiga & 134 \\
Vigías & 79 \\
Combinación & 60 \\
Guerrilla & 46 \\
Emboscada & 28 \\
Correr la línea & 16 \\
Total & 3807 \\
\hline
\end{tabular}

Se evitó contar por duplicado el registro de un mismo hecho. Sin embargo, un solo episodio puede reunir varias medidas ofensivas, como es el caso de las campañas.

Fuente: Base de datos RIA COLSON. http://sahuaro.colson.edu. mx:8087/RIAPublico/

una partida de vecinos de la Guardia Nacional o voluntarios, usualmente residentes del asentamiento afectado, la cual salía sobre la huella de los apaches y regresaba al punto de partida a las pocas horas.

Esta fue la medida utilizada por el juez local de Arivechi cuando en agosto de 1858 fue avisado por dos vecinos de que, en las inmediaciones del pueblo, los apaches habían 
dado muerte a "Da. Carmen Robles y tres mas familiares de la misma casa, saliendo un muchacho herido quien les avisó". En respuesta, el juez organizó a cuanta gente pudo armar para que saliera a la persecución. ${ }^{84} \mathrm{Del}$ mismo modo, a fines de enero de 1854, Manuel Landavazo, comisario de Horcasitas, organizó una persecución, de la cual reportó que:

El domingo p.p. a las tres de la tarde se me dio aviso por un vaquero del Rancho del Represo que estaba invadido este rancho por el enemigo apache.

De momento alisté una partida de quince hombres al mando de D. José Ignacio López quien salió prontamente, pero cuando llegó al citado rancho ya encontró la desgracia de que los bárbaros habían dado muerte a un hombre y una mujer.

López siguió en persecución del enemigo hasta un poco muy allá del [ilegible] de la Cruz de donde regresó al represo, y de este punto me dio parte de todo lo ocurrido" ${ }^{85}$

Para tener mayores posibilidades de encontrar a los apaches, la persecución debía hacerse con rapidez, por lo que esta medida se organizaba de forma urgente e improvisada en lo que a equipo bélico y combatientes se refiere. La alegada permanente escasez de recursos del erario público por el gobierno del estado fue un obstáculo para abastecer de forma adecuada a los vecinos que salían a realizar la persecución. A principios de marzo de 1861, el juez local de Rayón

${ }^{84}$ RIA, AGES, $E, P$, t. 327, Prefectura de Sahuaripa, correspondencia de marzo a diciembre, Sahuaripa, 19 de agosto de 1858. Trinidad Soto Mayor, juez $1^{\circ}$ local de Arivechi, al prefecto de Sahuaripa.

${ }^{85}$ RIA, AGES, $E$, $P$, t. 269 , s.e., f. 214.2, $1^{\circ}$ de febrero de 1854 . Manuel Landavazo, comisario municipal de Horcasitas, al prefecto de Ures. 
informaba sobre una incursión de apaches al prefecto de Ures, diciendo que:

[...] en los hogares de esta Villa se sacaron [los apaches] un robo de ganado, algunos bueyes y bestias caballares; organise de momento una corta partida de nacionales en numero de catorse armada esta cuasi [sic] con garrotes pues este nombre se les debe dar a la mayor parte de las armas con que se equiparon por lo extremamente fatales que se pudieron conseguir, en este estado marcharon en su persecución. ${ }^{86}$

La persecución era peligrosa, ya que se corría el riesgo de un contraataque apache a la partida que salía en su persecución o al asentamiento atacado inicialmente. ${ }^{87}$ Sin embargo, las autoridades locales consideraban importante realizar la persecución, ya que de esta manera era posible alejar a los apaches del lugar afectado, identificar el rumbo que tomaban para prevenir a otras poblaciones, y demostrar a los apaches que sus incursiones provocaban represalias, como lo informa el juez $2^{\circ}$ local de Santa Cruz al prefecto de San Ignacio: "Haciendo los mayores sacrificios he hechado [sic] fuera una partida de treinta hombres sin parque absolutamente[,] para hacer ver a los yndios que se les persigue, pero me quedo con el cuidado de que pueden sufrir un golpe" ${ }^{88}$

${ }^{86}$ RIA, AGES, $E, P$, t. 367, Prefectura del Distrito de Ures, Ures, 6 de marzo de 1861. Juez local de Rayón al prefecto de Ures.

87 RIA, AGES, E, $P$, t. 419, Magdalena, Magdalena, 28 de abril de 1869. Presidente municipal de San Ignacio a P. Ramírez, prefecto de distrito.

${ }^{88}$ RIA, AGES, $E, P$, t. 327, Prefectura San Ignacio 1858, agosto de 1858, San Ignacio, 7 de agosto de 1858 . Juez $2^{\circ}$ local de Santa Cruz al prefecto de San Ignacio. 
También la persecución se podía llevar a cabo a expensas de los particulares afectados por la incursión, por iniciativa propia o por instrucciones de la autoridad civil, siempre que tuvieran los recursos necesarios para ejecutarla. Un caso como el primero ocurrió en Bavispe, en agosto de 1874, cuando luego de la incursión de una partida de apaches a las labores, el presidente municipal informó que:

Ynmediatamente y con bastante violencia se destacó sobre ellos el C. Miguel Martinez con seis sirvientes y algunos vecinos y los persiguieron con mucha tenacidad hasta el Alamo, en donde se les hizo noche y conocieron que era imposible darles alcance porque iban amejorados [sic] del terreno y llevavan alguna ventaja, por lo que fue imposible escarmentarlos. ${ }^{89}$

\section{La campaña}

La campaña se organizaba cuando se tenía sospecha de la presencia de una ranchería de apaches en las serranías adyacentes a los pueblos, con el objeto de encontrarla y deshacerla. Esta medida era planeada con anticipación por alguna autoridad local y se componía por integrantes de la Guardia Nacional y vecinos voluntarios, ${ }^{90}$ fuerza preparada para tal fin, provista de armas, parque y víveres suficientes para los días que durara la operación, por lo que se requería de la dis-

${ }^{89}$ RIA, AGES, $E, P$, t. 458, Prefectura del Distrito de Moctezuma, Moctezuma, 25 de agosto de 1874. Presidente municipal de Bavispe al prefecto de Moctezuma, J. Aragón.

90 RIA, AGES, $E, P$, t. 427, Magdalena, 20 de febrero de 1870. Capitán de la $1^{\underline{a}}$ Compañía de flanqueadores de la villa de San Ignacio al prefecto del distrito. 
ponibilidad de estos recursos. Generalmente, duraba varios días, durante los cuales se recorrían puntos estratégicos seleccionados desde el principio de la acción. Una vez concluida, el jefe de la fuerza debía entregar al prefecto de distrito un diario de operaciones detallado. Esta medida tiene un carácter ofensivo y requiere de una organización más compleja porque en su marco se despliegan otras medidas ofensivas como la emboscada y el uso de vigías, guerrillas y exploradores, con la participación de vecinos residentes en varios asentamientos.

Así, a fines de marzo de 1870, el presidente municipal de Cumpas informó al prefecto de Moctezuma, José Aragón, acerca del regreso de "la partida de voluntarios que con objeto de ganar la gratificación de $\$ 200$ por cabellera de apaches se hallava [sic] situada en las inmediaciones de Santa Bárbara"; ${ }^{91}$ tres meses después, el prefecto Aragón giró instrucciones para organizar una campaña, recomendando al capitán Jesús Fimbres "que invite á cuantos quieran ir voluntarios á la campaña, debiendo estar seguros los \$200 por cabelleras y las sacas de las bestias que se represen". ${ }^{92}$

Para los vecinos que salían a campaña era importante el estímulo de las gratificaciones ${ }^{93}$ ofrecidas por el gobierno por las cabelleras de guerreros apaches ${ }^{94}$ y el ganado

91 RIA, AGES, E, P, t. 427, Moctezuma, 11 de abril de 1870. Presidente municipal de Cumpas a José Aragón, prefecto de Moctezuma.

92 RIA, AGES, E, P, t. 427, Moctezuma, 20 de junio de 1870. José Aragón, prefecto de Moctezuma, al C. Jesús Fimbres a cargo de la $2^{\text {a }}$ Compañía de fusileros de Cumpas.

93 RIA, AGES, E, P, t. 427, Magdalena, 30 de septiembre de 1870. P. Ramírez, prefecto de San Ignacio, al secretario de Estado.

94 Sobre el pago de recompensas por cabelleras de apaches en septiembre de 1870 “el C. Gobernador [...] ha tenido á bien disponer que del 
represado, manifestando en ocasiones abiertamente su interés en salir a campaña para obtener estas recompensas. ${ }^{95}$

\section{Partidas preparadas}

Son partidas provistas de bastimento y parque, y en ocasiones acuarteladas con el objeto de estar listas para salir inmediatamente después de recibir un reporte de incursión de apaches.

En marzo de 1855, Ygnacio Pesqueira, prefecto de Ures, mediante una carta cordillera ${ }^{96}$ envió instrucciones "a los comisarios municipales de cada pueblo de este Distrito [que] tuviesen lista y equipada de la mejor manera posible, una partida de hombres para que al primer aviso u ocurrencia que tuviesen sobre apaches saliesen en su persecución en los términos que VE se servirá ver por la adjunta copia [...]"; ${ }^{97}$

subsidio destinado por la ley de presupuestos generales para la defensa del Estado contra los barbaros se aumente el valor de la gratificación de las cabelleras en una mitad mas de la que se fijó por el presupuesto de egresos decretado por la Legislatura del Estado en 7 de Enero de este año", quedando en un total de 300 pesos. RIA, AGES, $E, P$, t. 422, Hermosillo, 28 de septiembre de 1870. Eleazar B. Muñoz, prefecto de Hermosillo, al secretario de Estado.

95 J. Aragón, prefecto de Moctezuma, informa al secretario de estado que estando en Bacerac lo esperaba "una reunion de 64 Ciudadanos[,] 38 de Bavispe y 26 de este pueblo que listos y voluntarios marchaban á campaña contra los bárbaros rumbo á la sierra de 'Guaynopa' a las órdenes del C. Eusebio Samaniego" y dice constarle "de vista el entuciasmo contra los apaches[,] interesados á la recompensa de cabelleras". RIA, AGES, $E, P$, t. 427, Bacerac, 16 de octubre de 1870.

${ }_{96}$ Arcaísmo por circular.

97 RIA, AGES, $E, P$, t. 283, Ures, 12 de abril de 1855. Ygnacio Pesqueira, prefecto de Ures, a los comisarios de su distrito. 
un mes después Rafael Ángel Corella, prefecto de Arizpe, informó al gobernador sobre esta medida ofensiva:

A las ocho de la noche del día 19 del corriente recibí por cordillera muy violenta un oficio del comisario municipal de Bacanora, en él, me da parte que los bárbaros en gran número estaban en la congregación de Suaqui e intentaban atacarlo. En el momento por correo violento mandé que del pueblo más inmediato que es el de Aconchi, salieran 30 hombres que de anterioridad tenía acuartelados y unidos a otros 30 en Baviácora a las órdenes del Subteniente de Urbanos, D. Francisco Toyos, [a] auxiliar los pueblos y congregaciones amagados, inter yo en persona me presentaba con los auxiliares de este pueblo y el de Huépac que también tenía acuartelados. ${ }^{98}$

En octubre de 1856, el gobernador ordenó al juez local de Buenavista:

Inmediatamente que reciba U. la presente orden, hará que se acuartelen todos los vecinos de esta villa que estén en aptitud de llevar las armas cuya fuerza creo suficiente para la seguridad del vecindario en concepto de que es estese [sic] pendiente de los movimientos del enemigo para acudir a su defensa en caso necesario. ${ }^{99}$

La mayor dificultad para ejecutar esta medida era la escasez de recursos para sostener a la fuerza acuartelada.

${ }_{98}$ RIA, AGES, E, $P$, t. 283, Banámichi, 23 de abril de 1855. Rafael Ángel Corella, prefecto de Arizpe, al gobernador del Estado.

99 RIA, AGES, $E, P$, t. 288, Juzgados y Ayuntamiento, Juez Local de esta villa de Buenavista, Buenavista, 24 de octubre de 1856. El gobernador al juez local de Buenavista. 
Durante el periodo abordado en la investigación, 18541890 , son frecuentes las quejas de las autoridades civiles por la falta de armas y bastimentos para equipar a las partidas que salían en persecución de los apaches. Esto entorpecía la posibilidad de mantener una fuerza lista para cualquier emergencia, como lo expuso en abril de 1855 el prefecto de Moctezuma José Terán y Tato: “[...] la gente que se puede reunir apenas puede estar a la defensiva; amás no puede ser suficiente para perseguir, lo primero por que es poca y no dan tiempo para reunir de los demás pueblos del Distrito. Lo segundo que no se pueden tener en reunión por que no hay con que sostenerlos". ${ }^{100}$

\section{La cortada}

La cortada es una respuesta rápida, que ataja y cierra el paso a las partidas de apaches. Su principal objetivo es represar robos de ganado. Para ejecutarla se requiere que los vecinos y las autoridades encargadas de la operación conozcan de antemano los caminos de entrada y salida más utilizados por los apaches para hacer sus incursiones y retornar a Estados Unidos con el botín.

Durante una cortada, la fuerza se destacaba en algún punto del camino, por delante de los apaches, para cerrarles el paso, atacarlos y represarles el robo cuando iban de regreso. "Cortar huella" se refiere a encontrar huellas de apaches, con o sin robo, en operaciones de exploración. En seguida,

100 RIA, AGES, $E, P$, t. 283, Moctezuma, 23 de abril de 1855. José Terán y Tato, prefecto de Moctezuma, al gobernador del Estado. 
incluimos tres casos en los que el término cortada se utiliza de manera explícita.

A principios de abril de 1860, luego de varios reportes de incursiones apaches a inmediaciones de Opodepe, Rayón y otros asentamientos, Francisco Barragán, juez 1ํ local de Opodepe, organizó algunas partidas de vecinos y Guardia Nacional para cortar la salida de los apaches, y dispuso el día 7 de:

[...] una partida de 20 nacionales y di orden que salieran 10 nacionales de la jurisdiccion de Merecichi por donde ce reunieron 30 hombres y 15 que ce agregaron de Rayón y les di orden ce cituaran en las salidas mas conocidas del enemigo, aci lo berificaron como ce les ordenó[,] pero los barbaros tomaron otro rumbo como en direccion á Cinoquipe por donde no ce pudo lograr un echo que declarabamos; la gente no solo ce cituo en el parage ó salida conocida sino que andubo tres ó cuatro dias cortando por distintos rumbos, pero el enemigo abia quedado atrás y abia cambiado de direccion, los nacionales regresaron á este a los seis dias sin lograr encontrarlos. ${ }^{101}$

Con el mismo objeto, en marzo de 1861, Rafael Buelna, prefecto de San Ignacio, envió una orden a los jueces de San Ignacio, Terrenate e Ímuris "para que movieran tambien algunas partidas á tomarle la vanguardia al enemigo”. Sobre el resultado de la operación informó que “Todo se hizo con la mayor violencia, pero no se logró dar alcance á los barbaros, por que cuando llegaron las primeras fuerzas a cortarles

101 RIA, AGES, E, P, t. 348, Ayuntamientos y jueces locales, Opodepe, 13 de abril de 1860 . 
la retirada, ya habian traspasado la Linea". ${ }^{102}$ Esta observación señala cómo el lado estadounidense de la frontera servía de santuario a las partidas apaches que regresaban de depredar el lado mexicano.

El 28 de agosto de 1861, Antonio Federico, juez local de Cucurpe, reportó una cortada que cumplió su propósito:

Á las ocho de la mañana del 26 de este, recibí aviso que una partida de apaches habia levantado del Rancho de la Peña, (distante de la Villa media milla) en la madrugada del mismo dia[,] un robo de ganado mayor. Inmediatamente mandé alistar una partida de Nacionales bajo las ordenes del Tente. de G. N. Dionisio Teutemes para que saliese en su persecución. La salida de los nacionales se efectuó á medio dia, saliendo dho. Tnte. con 23 nacionales (18 ynfantes y 5 dragones). Hoy á las nueve del dia regresó la fuerza, habiendo quitado á los apaches, á mas del robo que llebaban de la Peña, un robo de sesenta y cinco cabezas entre ganado y bestias. El Tnte. Teutemes me ha dado parte verbal de lo acontecido en la cortada, cuyo tenor transcribo a V.E. para su aprobación.

\section{$[\ldots]$.}

He tenido á bien repartir entre la misma tropa las bestias caballares[,] mulares, y burros entre tanto [a]parezcan sus dueños, considerando que asi mas bien se libertarán del enemigo apache que no tenerlos juntos. El ganado, he puesto en pastoria bajo el cuidado del C. Jose Miranda pagandole su trabajo. Acompaño á V.S. la reseña del robo para sus fines consiguientes, sirviendose VS. decirme si debo exigir á los dueños alguna recompensa, ó saca como antes se acostumbraba para hacer una

102 RIA, AGES, E, P, t. 367, Prefectura del Distrito de San Ygnacio, Magdalena, 20 de marzo de 1861. Rafael Buelna, prefecto de San Ygnacio. 
gratificación a la tropa para que salgan aun con mas empeño en otra cortada que se ofrezca. ${ }^{103}$

\section{Exploradores}

Los exploradores eran pequeñas partidas que se enviaban al lugar afectado por las incursiones apaches, con el objeto de verificar los hechos, explorar el lugar y conocer por la huella el número de apaches y el rumbo que habían tomado. Los exploradores operaban mientras las autoridades locales organizaban una partida para realizar la persecución.

También durante las campañas se enviaban partidas de exploradores para rastrear huellas de los apaches por delante de la fuerza principal, como se comunica en los siguientes extractos de reportes de incursiones ocurridas entre 1869 y 1871.

Por diferentes noticias dadas por los exploradores que esta Prefectura ha tenido en observancia de los apaches, se bino en conocimiento de que [en] la Sierra del Chupurate contigua á la del Alamo, y Chanate existian aquellos, [...]. ${ }^{104}$

El Sr. Garcia le dio aviso á esta Presidencia y dispuse que cinco nacionales salieran en el acto a reconocer[,] los cuales siguieron la huella hasta donde se desengañaron que los bárbaros se dirigian al interior y se devolvieron. ${ }^{105}$

103 RIA, AGES, E, P, t. 367, Prefectura del Distrito de Ures, Cucurpe, 28 de agosto de 1861. Antonio Federico, juez local de Cucurpe. Paréntesis en el original.

104 RIA, AGES, E, P , t. 416, Altar, 12 de febrero de 1869. Miguel Zepeda, prefecto de Altar, al secretario de gobierno.

105 RIA, AGES, E, P, t. 427, Moctezuma, 9 de agosto de 1870. El presidente municipal de Guásabas al prefecto de Moctezuma. 
[...] se me dá parte, que los indios asaltaron a dos vaqueros de D. José M. Gastelum, en el campo de Bavocomari, dando muerte a Julio Palomino, y salvandose el otro milagrosamente. Desde luego hise salir los nacionales que puede alistar de momento, al mando del Teniente Franco. Martines, quien reconocida que fue la hueya, considero que la fuerza que llebaba y constaba de siete nacionales, no era bastante por ser el numero de indios de alguna consideración [...]. ${ }^{106}$

\section{Destacamento}

Un destacamento es una partida ubicada durante una temporada en un punto determinado, por lo general un lugar estratégico en las inmediaciones de los pueblos, para dar una respuesta rápida a las incursiones apaches. Por ejemplo, durante el mes de enero de 1870, las incursiones apaches se hicieron sentir en el distrito de Arizpe, por lo que a principios de febrero el prefecto Eduardo Toyos dio la orden de “[...] poner una partida de 25 nacionales en el punto llamado 'Labadero' y que esta permaneciera por doce dias por ser uno de los puntos mas seguros de entradas y salidas de los barbaros”. ${ }^{107}$ De igual modo, el prefecto de Moctezuma recibió la orden de destacar "una partida considerable contra los barbaros en el punto que convenga”. ${ }^{108}$

106 RIA, AGES, E, P, t. 432, Prefectura de Altar, Altar, 24 de agosto de 1871. El presidente municipal de Tubutama al prefecto de Altar Miguel Zepeda.

107 RIA, AGES, E, P, t. 426, Delicias, 20 de febrero de 1870. Eduardo Toyos, prefecto de Arizpe, al gobernador.

108 RIA, AGES, E, P, t. 427, Moctezuma, 16 de mayo de 1870, J. Aragón, prefecto de Moctezuma, al secretario de Estado. 
Luego de recibir el aviso de que los apaches pasaban "con un robo considerable de caballada en direccion de la sierra de Milpillas", el prefecto de Sahuaripa dictó las órdenes correspondientes para organizar destacamentos que se apostaran en las salidas probables de los apaches:

La fuerza de Bacanora cubre el punto que se le indicó; diez nacionales de Tarachi estan situados en Matarachi y otros diez estan en la Sierra de los "Orcones"; nacionales de Arivechi estan cubriendo la salida que se les señaló; y el Capitan Hurtado la salida de la "Casita", sin saberse asta ahora el resultado, el cual no confia esta Prefectura que sea como se desea, por que no habiendo fuerza que persiga por la retaguardia á los salvages, por que la falta de armas no há permitido hacerlo, es muy facil que burlen la vigilancia de las partidas de nacionales que los esperan apostados en sus puntos. ${ }^{109}$

\section{Fatiga}

Se le llamó fatiga a una medida ejecutada por una partida organizada rápidamente, con poco o ningún bastimento, que sale en persecución de los apaches durante más de un día, a diferencia de la persecución que regresa a las pocas horas. En ocasiones se nombra de este modo a una persecución llevada a cabo con mucha dificultad, que resulta extenuante.

En diciembre de 1855, una partida de vecinos realizó una operación de este tipo, acerca de lo cual Jesús Rodríguez, jefe de la fuerza, reportó desde Pozo:

109 RIA, AGES, E, P, t. 398, Prefectura de Sahuaripa, Sahuaripa, 19 de abril de 1867. El prefecto de Sahuaripa, J. N. Cruz, al gobernador. 
[...] me vine a donde me notician que son seguros el bárbaro apachi, así que me desengañe y que no había nada y me vine para el pozo abastimentarme por que hace cuatro días que no traíamos los soldados un adarme de bastimento[,] pues no espero mas de el bastimento para marchar para el Chino[,] que me aseguran que allí recalan con los robos que se sacan de la ciudad. ${ }^{110}$

Por sus características, la fatiga es una medida ofensiva intermedia entre la persecución y la campaña: al igual que en la persecución, el contingente sale de improviso, sin bastimento ni armamento adecuados; en similitud con la campaña, la fatiga recorre los puntos donde sus integrantes creen que los apaches se encuentran; además, puede hacer operaciones en combinación con partidas de otros pueblos.

En la fatiga es necesario que el abasto de alimentos y otros recursos se realice en el campo, mientras la fatiga sigue su itinerario, todo es sobre la marcha, no hay parada para abastecerse:

Los vecinos de estos pueblos[,] E.S., son muy pobres: casi diariamente andan en fatiga sin tener lugar a dedicarse a sus negocios particulares. Este motivo hace que muchas veces salgan sin bastimento; por lo que sería conveniente si fuera del Superior agrado de VE me diera trescientos pesos para mantenerlos en seguro depósito y dedicarlos exclusivamente para abastimentar las partidas que hay que mover violentamente cuando el caso lo requiera; igualmente el parque que fuese de su superior agrado, pues de este artículo carecen todos los pueblos. ${ }^{111}$

110 RIA, AGES, E, P, t. 283, Pozo, 13 de diciembre de 1855. Jesús Rodríguez. Presumiblemente Pozo es un pequeño asentamiento ubicado en el distrito de Arizpe.

111 RIA, AGES, E, $P$, t. 283, Banámichi, 27 de febrero de 1855. Rafael Ángel Corella, prefecto de Arizpe, al gobernador del estado. 


\section{Vigias}

Se les llama vigías a los centinelas o a una partida pequeña que tiene como objeto detectar noticias de apaches y observar sus movimientos en las cercanías de algún asentamiento o de alguna fuerza en campaña. Por ejemplo, después de que los apaches realizaron dos incursiones en los pueblos del distrito de Arizpe durante los días 24 y 25 de febrero de 1855, la primera acción del prefecto fue enviar una partida de vigías: "dispuse en el acto una partida de veinte hombres al mando del comisario, para que observara los movimientos del enemigo, interin me ocupaba de alistar una fuerza". ${ }^{112}$

La misma medida fue utilizada por el comandante militar de Opodepe, en junio de 1857, quien después de salir en persecución de una partida de apaches relató: "puesto en la huella[,] destaqué vigías a una distancia proporcionada[,] siguiendo sobre ella hasta las doce del mismo día en que se me dio aviso por los vigías que por sus observaciones el enemigo debiera estar en la Agua del Güerigo [...]". ${ }^{113}$ Un hacendado en San Marcial, distrito de Ures, reportó en octubre de 1857: "[...] en el punto del Veranito ha caído una partida de Apaches a pie llevándose veinte y cuatro bestias mansas del corral, se han mandado dos vigías veer el rumbo que toman y veer $[$ sic $]$ si se pueden perseguir $[\ldots]$... ${ }^{114}$

112 RIA, AGES, E, $P$, t. 283, Banámichi, 27 de febrero de 1855. Rafael Ángel Corella, prefecto de Arizpe, al gobernador del estado.

113 RIA, AGES, $E, P$, t. 307, Opodepe, 30 de junio de 1857. Epifanio Barragán, comandante militar de Opodepe, al prefecto de Ures.

114 RIA, AGES, E, $P$, t. 306, 1857, Correspondencia Prefectura de Ures. enero a diciembre, mes de octubre, Mátape, 14 de octubre de 1857. Manuel Gutiérrez, dueño de la hacienda de San Marcial, al prefecto de Ures. 


\section{Combinación}

Es la medida ofensiva que consiste en la coordinación de dos o más partidas de distintos pueblos, cada una con un jefe, con el fin de realizar la persecución de una partida de apaches, por distintos rumbos. Su objetivo principal es cubrir la mayor parte del terreno en el menor tiempo posible. Así, para escarmentar a una partida de entre 15 y 20 apaches que habían causado varias muertes en el distrito de Sahuaripa, a fines de mayo de 1870, el prefecto informó que "[...] se dió orden á los C.C. Presidentes municipales de Arivechi y Valle de Tacupeto, para que destacaran una partida de quince á veinte nacionales de cada pueblo, y tomando la huella del enemigo, lo persiguieron en combinación hasta desalojarlo del Distrito". 115

En la combinación se señala el asentamiento de origen de los vecinos combatientes, dándole a los pueblos estatus de unidades territoriales de defensa. Por ejemplo, en octubre de 1856, el prefecto de Hermosillo envió cinco hombres a reforzar una partida que el celador del Monte del Seri había organizado en persecución de una partida de apaches. Al mismo tiempo, informó haber dado "orden al Capitán de la Compañía de Nacionales del Pueblo de Seris, Dn. Juan Moreno, para que con la gente de caballería del Aguaje saliesen a perseguirlos en combinación con los [del] Zubiate que también puse a las suyas $[\ldots]]^{116}$

115 RIA, AGES, $E$, $P$, t. 427, Sahuaripa, 27 de mayo de 1870. J.N. Cruz, prefecto del distrito de Sahuaripa, al secretario de Estado.

116 RIA, AGES, E, P, t. 285, Hermosillo, $1^{\circ}$ de octubre de 1856. Fernando Rodríguez, prefecto de Hermosillo, al gobernador. 
Durante las operaciones de combinación es común que se unan las partidas bajo el mando de un solo jefe, para constituir una fuerza mayor, como es el caso siguiente. El 20 de diciembre de 1858 el presidente municipal de Huásabas informó a Rafael Buelna, prefecto de Moctezuma, que después de recibir el reporte de una incursión de apaches destacó una partida de Guardia Nacional al mando del teniente Jesús Fimbres, al tiempo que solicitó gente al pueblo de Granadas, entre los cuales venía el ciudadano D. Ygnacio Ramírez. Ambas fuerzas hacían un total de 32 hombres, los cuales formaron una combinación bajo el mando de este último "atendiendo a la experiencia y buenas disposiciones de Ramírez, sin dar motivo de sentimiento ni el enunciado teniente, ni el resto de la guardia por no ser éste último de ella". ${ }^{117}$

\section{Guerrilla}

Guerrilla es una de las partidas menores en que se divide la fuerza principal durante una campaña, como lo informó Juan Fimbres, jefe de una partida de vecinos de la Villa de Moctezuma, que salió a campaña tras los apaches en diciembre de 1869:

El día 12 del corriente, emprendi mi marcha de esta Villa, cosa de la una de la tarde, con 40 hombres equipados y una mula cargada de bastimento, rumbo al norte ó sierra de madera de esta villa, y obsequiando las instrucciones que recibi de esta Prefa. dispuse á mi marcha el servicio, abanzando desde luego

117 RIA, AGES, E, $P$, t. 343, Prefectura de Moctezuma, 1859, Moctezuma, 22 de diciembre de 1858. Rafael Buelna al S. Ynspector de la Frontera. 
las correspondientes vijillas [vigías], colocando en distancias la guerrilla, vanguardia y retaguardia, alcanzando hacer noche en el potrero de los Gecoris. ${ }^{118}$

La guerrilla se caracteriza por la rapidez para maniobrar, y realiza su función separada de la fuerza principal, como lo apuntan los ejemplos siguientes. En noviembre de 1870 , asentó en su diario de operaciones el comandante de la compañía de voluntarios en campaña contra los apaches en el distrito de Moctezuma:

Seguí en el mismo órden del dia anterior; por la noche mandé la guerrilla con sus respectivos vigías[,] dándoles órden que reconocieran el cajon de "Guaynopa"[,] citándoles punto de reunion en los “Taraisitos". En el mismo acto me moví con el resto de la fuerza[,] tomando el rumbo del Espúnaro dollado [sic] y avancé hasta el cajon de las trincheras. ${ }^{119}$

En junio de 1871, el jefe de operaciones de la campaña en la sierra de Guaynopa reportó al prefecto de Moctezuma: "Desde luego mandé una guerrilla de 10 hombres al mando del Sargento habilitado Lorenzo Acuña, con las instrucciones convenientes, con órden de que cortara las salidas del Valle del Satachi, cajon del Cesar, continuando yo mi marcha con el resto de la fuerza rumbo al Oriente". ${ }^{120}$

118 RIA, AGES, E, $P$, t. 419, Moctezuma, 21 de diciembre de 1869. Juan Fimbres, jefe de la campaña, al prefecto de distrito.

119 RIA, AGES, E, P, t. 427, Moctezuma, 30 de noviembre de 1870. Comandante de la compañía de sesenta y cuatro voluntarios que la emprendieron sobre la sierra madre de "Guaynopa” contra los bárbaros, a Eusebio G. Samaniego, prefecto de distrito.

120 RIA, AGES, E, $P$, t. 434, 1871, Prefectura de Moctezuma, Nácori, 15 


\section{Emboscada}

La emboscada consiste en esconderse en las inmediaciones del rumbo que se cree que van a tomar los apaches, para atacarlos por sorpresa. Los apaches practicaban frecuentemente emboscadas. Ha sido propuesto que los vecinos de los asentamientos fronterizos aprendieron de los apaches a practicar la guerra de guerrillas para atacar, en pequeñas unidades, por sorpresa al adversario. ${ }^{121}$

El uso de esta medida en el contexto de una campaña se reporta por Rafael Ángel Corella, al frente de vecinos del río Sonora en julio de 1855: "Luego que amaneció mandé reconocer todos los cerros inmediatos y ya nada se encontró, a las ocho de la mañana continué mi marcha rumbo al norte, dejando allí una emboscada de 30 hombres por si los indios volvían a su ranchería [...]”. ${ }^{122}$

El Juez $1^{\circ}$ local de Opodepe informó al prefecto de Ures, en septiembre de 1857, de la fatiga que practicaba una partida al mando del vecino Pedro Paes, donde se recurrió a emboscar a los apaches:

[...]. Ayer como a las siete de la noche salió a este punto un joven hijo de D. Antonio Ynclán que se hallaba trabajando en la Mina del Socorro, y dio aviso de haber visto pasar por el mismo Socorro una partida de Apaches con algún robo de

de junio de 1871. Marcelo López, jefe de las operaciones de la campaña de voluntarios que hizo con 40 nacionales contra los bárbaros de la sierra de Guaynopa, al prefecto de Moctezuma.

${ }_{121}$ Alonso, Thread of Blood, pp. 26-32.

122 RIA, AGES, E, P, t. 283, Arizpe, julio 10 de 1855. Rafael Ángel Corella, jefe de "Operaciones de la Campaña que con 85 hombres del rio de Sonora emprende $[\ldots]$ contra los bárbaros”. 
caballada: inmediatamente el celador de este mineral D. Dolores Ruiz se puso a la cabeza de unos doce vecinos que de pronto reunió y me consignó la persecución de dichos bárbaros. Como a las nueve de la misma noche partí con la mencionada fuerza por el rumbo que llaman Salsipuedes, a la parte de la Sierrita por donde creí infalible la salida de los indios, y a fin de observarlos destiné dos exploradores, cosa de media noche poco mas[,] llegué al punto de las Rastritas donde me pareció indispensablemente hacer alto para observar al enemigo, $y$ poniendo vigías pernoctamos alli, de donde al alba del día mandé dos hombres de acaballo reconocer la salida, y visto a los indios por el de la Sierrita dispuse una emboscada por donde creía que debían salir, pero la astucia de los perversos indios los hizo cambiar de rumbo, y cuando los descubrimos ya venían por nuestra retaguardia, $[\ldots]$ aunque tampoco se les disparó por la fatalidad de las armas que todas estaban inútiles y los indios al fin se salvaron huyendo merced también a los buenos caballos en que iban montados $[\ldots] .{ }^{123}$

\section{Correr la línea}

Se llama correr la línea al patrullaje a través de una serie de pueblos y puntos geográficos, que componen un territorio delimitado de antemano por consenso de las autoridades locales y los vecinos, como se aprecia en los siguientes casos. En octubre de 1857, el prefecto del distrito de Ures, J. Juan Elías, informó: "He puesto cincuenta nacionales de estos puntos, Nácori, Mazatán y Pueblo de Alamos para

${ }^{123}$ RIA, AGES, $E$, $P$, t. 306, 1857, Correspondencia Prefectura de Ures enero a diciembre, mes de septiembre de 1857, Ures, 4 de septiembre de 1857. Parte de Pedro Paes al Juez $1^{\circ}$ local de Opodepe y éste a Ramón Zúñiga, prefecto de Ures. 
que corran la línea cubriendo las entradas y salidas mas frecuentadas de los indios bárbaros[,] situando un piquete de diez hombres en los Tanquis auxiliados en caso de ser necesario con el Admor. del rancho viejo". ${ }^{24}$

El mismo prefecto reportó en septiembre de 1858: "En comunicación de 30 del mismo mes dice á esta Prefectura el Señor Juez local de Mazatan, que los veinticinco hombres que corrian la linea de Nácori a las inmediaciones de Tecoripa habian regresado el dia 27 sin ninguna novedad [...]". ${ }^{125}$ Investigaciones subsecuentes podrían aclarar si el trazo de estas líneas contribuyó a definir los límites municipales y distritales reconocidos formalmente después. Por lo pronto puede afirmarse que correr la línea fue una medida que tejió vínculos entre vecinos de distintos asentamientos.

\section{MEDIDAS DEFENSIVAS}

Se recurrió a las medidas defensivas con menor frecuencia que a las ofensivas de acuerdo con las fuentes. Consideramos que esta distribución estuvo influida porque el conflicto no distinguió entre combatientes y no combatientes, así el escenario más reiterado en las fuentes es el de las incursiones apaches que atacan por sorpresa a la población de vecinos cuando está dedicada a las labores del campo, dispersa y desarmada.

124 RIA, AGES, E, P, t. 306, 1857, Correspondencia Prefectura de Ures enero a diciembre, mes de octubre, Ures, 12 de octubre de 1857. J. Juan Elías, prefecto de Ures, al gobernador.

125 RIA, AGES, E, P, t. 328, septiembre de 1858, Prefectura del Distrito de Ures, Ures, 2 de septiembre de 1858. J. Juan Elías, prefecto de Ures, al gobernador. 
La ejecución eficaz de las medidas defensivas requería que la autoridad local tuviera conocimiento anticipado de la incursión, para prevenir a los vecinos que se encontraban en las inmediaciones del pueblo o en sus casas y disponer su protección. El carácter sorpresivo observado por las incursiones apaches impedía tener conocimiento previo del ataque, lo que, sumado a la escasez de recursos para equipar a la Guardia Nacional y para armarse los propios vecinos, dificultaba poner en práctica medidas efectivas para prevenir o disminuir los daños que las incursiones apaches infligían a los vecinos.

Las medidas defensivas identificadas tienen por objetivo proteger la vida de los integrantes de las familias de los vecinos. En este tipo de medidas, pasa a segundo plano el resguardo de los bienes de campo. De ello se encarga la fuerza armada que sale tras los apaches, ya sea en la modalidad de persecución como en la de fatiga.

Las autoridades locales eran las responsables de organizar las medidas defensivas y las fuentes muestran que tomaban disposiciones para proteger de las incursiones apaches a los habitantes de los vecindarios a su cargo.

La vida cotidiana de buena parte de los habitantes de la frontera estaba enmarcada en el ámbito campesino, de modo que las familias trabajaban en el campo, cerca de los pueblos, en actividades agrícolas y ganaderas, en la recolección de frutos silvestres y otros recursos como agua, leña y palma y en la caza menor, siguiendo los ciclos a lo largo del año. Cabe subrayar que las actividades relacionadas con la pequeña minería, como la minería de placer, implicaban la dispersión de los gambusinos. ${ }^{126}$ Para realizar estas

126 Shelton, From Tranquility and Order, p. 14. 
actividades la población se diseminaba en los alrededores del asentamiento, por lo que era difícil hacer del conocimiento general una repentina incursión de apaches. De ahí el recurso a la detonación producida por una pieza de artillería o a tocar generala.

Identificamos las siguientes medidas defensivas: detonación o salva de una pieza de artillería, tocar generala, escoltar viajeros y resguardar la población en lugares apropiados.

\section{Detonación producida por una pieza de artillería}

La detonación, trueno o salva producidos por un cañón $u$ otra pieza de artillería advertía a la población dispersa de una incursión apache inminente para que tomara precauciones.

Así, están dos ejemplos registrados en el presidio de Santa Cruz, contiguo a la línea fronteriza con Estados Unidos. El 4 de agosto de 1858, Trinidad Michelena, el juez $2^{\circ}$ local, comunicó lo siguiente:

Desde el mes de Mayo estoy pidiendo algunos auxilios a la Jefatura de parque y armas, y no epodido conseguir ni una cosa ni otra.

La situación que guardamos es espantosa, y estamos expuestos a ser víctimas de los bárbaros por estar enteramente desprovistos de armas y municiones. Los pocos Nacionales que tengo estan todos diseminados en sus Labores, y hasta el recurso de avisarles en caso decer atacado, se me acortado, con haberse llevado las dos piezas que tenía el Precidio. Una la tiene el Sr. D. José Ma. Elías en Cocóspera, y la otra esta en San Ignacio.

Ace seis dias Emo. Sor, que me mataron un Padre de numerosa familia a horias [a orillas] del Pueblo, y hoy por que la pro- 
videncia es grande, se libertaron cuatro vecinos de un fuerte ataque que les dieron 19 indios bien montados y mejor armados. ${ }^{127}$

Tres días después, el 7 de agosto de 1858, el juez insistió en la petición de auxilio, en especial del envío de la pieza de artillería, sumando nuevos agravios y precisando los anteriores:

Desde Mayo pedí algunos pertrechos de guerra a esa Prefectura, y es la hora en que nada he visto.

Hace 8 dias que mataron a un vecino a horillas del Precidio, y hoy han sido atacados otros cuatro por una partida de 19 Apaches bien montados[,] mejor armados, los que se libertaron merced á la providencia, yo acudí violentamente con el Vecindario que pude reunir y salbé las victimas que se habrian inmolado de ese furor[,] en la refriega quedó un Yndio muerto y aseguran fueron dos mas heridos.

Haciendo los mayores sacrificios he hechado fuera una partida de treinta hombres sin parque absolutamente para hacer ver a los yndios que se les persigue, pero me quedo con el cuidado de que pueden sufrir un golpe[,] aunque las ordenes que lleva el Gefe son de regresar lo mas tarde mañana.

No puedo emprender ninguna cortada con esperanzas de buen ecsito por estar muy falto de armas, y sin un solo cartucho[,] VS [Vuestra Señoría] tendrá la vondad de auxiliarme con unas sien [sic] paradas y la pieza que tiene en esa $\mathrm{Pa}$. [Pla$\mathrm{za}$ ] poderme poner acubierto [sic] siquiera de un completo descalabro.

127 RIA, AGES, E, P, t. 313, Ayuntamientos y Jueces locales del Estado, 18 de agosto de 1858, Santa Cruz, 4 de agosto de 1858. Trinidad Michelena, juez $2^{\circ}$ de paz de Santa Cruz, al gobernador. 
[...]. La pieza que le pido a VS es una de las cosas que me hace mas falta pues con ella doy aviso a los vecinos que estan en sus quiaseres $[$ sic $]$ cuando el enemigo se aprocsima $[\ldots] .{ }^{128}$

\section{Tocar generala}

En la época, "tocar generala” era un aviso dado con instrumentos de viento y percusión. Al parecer, el instrumento musical al que más se recurrió en la región fue la trompeta. Era un toque para que la gente que tuviera armas las preparara y acudiera a ponerse a las órdenes de la autoridad local, estuviera enlistada o no en cuerpos organizados, y la población se alertara.

En las fuentes de esta base de datos, "tocar generala" se utilizaba como el último recurso, cuando otros medios no habían funcionado o no eran posibles. Es de observarse que en las fuentes no se menciona tocar a rebato la campana del templo, por razones que desconocemos.

Los ejemplos que siguen ilustran el uso de "tocar generala" como medida defensiva, para convocar a las armas y alertar a la población. Así, en Hermosillo, en febrero de 1855, el comandante general del distrito se dirigió al gobernador y comandante general del departamento en los siguientes términos:

Tan luego como recibí la comunicación de VE. fha 2 del corriente que por extraordinario se sirvió remitir a esta coman-

128 RIA, AGES, $E, P$, t. 327, Prefectura San Ignacio 1858, agosto de 1858, San Ignacio, 7 de agosto de 1858. Parte inserto de Trinidad Michelena, juez $2^{\circ}$ de paz de Santa Cruz, en Juan Antunez, prefecto de San Ignacio, al gobernador. 
dancia y la cual fue en mi poder a las tres de la tarde del siguiente día tres, en virtud de no contarse en la actualidad con las compañías Urbanas de esta ciudad por hallarse estas en el mayor desarreglo, me fue preciso pedir al Sr. Prefecto de éste Distrito por medio de una comunicación en la que al efecto \{se inserta\} la de VE, cuarenta vecinos montados, su mayor número si era posible, e igualmente pedí a los comandantes de dhas compañías por medio de una comunicación oficial en la que les manifesté de la manera mas patente la urgentísima necesidad que había de que cooperaran activamente en el alistamiento de la fuerza que les demandaba, cuya orden emanaba de esa superioridad. Mas no habiendo dado ningún resultado esta medida a las ocho de la noche y recibido a esa hora de la prefectura una comunicación en que manifestaba no poder poner a disposición de esta Comandancia ni un solo hombre de los que se le pedían en virtud de que todos eran urbanos, a excepción de los empleados, me vi en el caso de mandar tocar generala a esas horas, lo que había omitido por no poner en alarma a la población, pero ni aún esto me dio buen resultado, porque no se presentó en el cuartel un solo individuo. ${ }^{129}$

Un hecho registrado en el distrito de Moctezuma el 3 de marzo de 1870 muestra que las incursiones apaches afectaban a miembros de la élite del estado de Sonora y constata la dispersión de la población.

El dia 3 del corriente á cosa de las ocho de la mañana y en el punto nombrado bajio de Peravavi[,] camino de esta Villa á Cumpas, fueron asaltados por cinco apaches el Ciudo.

129 RIA, AGES, E, $P$, t. 283, Hermosillo, 9 de febrero de 1855. Comandante general del Distrito de Hermosillo al Gobernador y comandante general del Departamento de Sonora. 
Diputado Roman Roman y los Ciudos. Fernando Arvizu, José Durazo hijo y otros tres mas que reunidos hacian su camino para ésta[,] en cuyo asalto fue herido el Ciudo. Roman Roman[,] pasandole una bala la parte superior del muslo derecho y llevandose los bárbaros dos bestias mulares [...].

Tan luego como esta Prefectura tuvo la noticia mando tocar generala y no concurrieron mas de cinco soldados que mandé con los interesados á levantar los trastos destrosados por los bárbaros, pues tocó la desgracia que ese dia toda la mas gente de esta cabecera andaba fuera[,] por cuyo motivo no se persiguieron los indios. ${ }^{130}$

\section{Escoltar viajeros}

La existencia de molinos de harina de trigo en los pueblos de las cuencas de los ríos Sonora y Altar y el número significativo de topónimos con el nombre de "galera" -en su acepción de almacén de granos y que una porción de ellos estuviera prevista para satisfacer las necesidades del “común”-, sugieren que existió una tendencia a la autosuficiencia alimentaria, al menos en el cereal de mayor consumo, y por la especialización ganadera de la región había una disponibilidad general de carne vacuna y de leche, y de los productos de ésta, desde los ranchos y haciendas hasta los pueblos y villas, donde en proporción considerable las casas contaban con corral. El miedo a salir del asentamiento provocado por exponerse a los riesgos de muerte o asalto, atribuidos a los apaches, influyó parcialmente en la práctica

130 RIA, AGES, E, P, t. 427, Moctezuma, 7 de marzo de 1870. J. Aragón, prefecto de Moctezuma, al secretario de Estado. 
de la endogamia y en evitar salir del asentamiento, a menos de hacerlo en grupo, mientras más numeroso mejor. ${ }^{131}$

Aun así, la necesidad de intercambio obligaba a circular por otros asentamientos, como se expresa en el siguiente caso:

Por mas que esta Prefectura activa sus providencias para hacer una constante persecución á los apaches, y que las autoridades de los pueblos correspondan á ellas, poniendo en accion partidas de nacionales que cubren las entradas y salidas mas conocidas, no obstante la escasez de armas, si en esta vez se há conseguido hasta la fecha que no levanten robo, no han podido evitarse las desgracias con los ciudadanos que transitan de un punto á otro del Distrito. Esta fatalidad es lamentable ciertamente; pero inevitable, por la estrema necesidad que tienen los pobres moradores de estos pueblos de salir bien ó mal acompañados según su posibilidad, á sus diligencias particulares. ${ }^{132}$

Ante el carácter inevitable de trasladarse a otros asentamientos, se viaja en grupo, en "convoy" se dice en la época:

Ayer á las ocho de la mañana en que llegué á esta cabecera se me dio parte por el C. Candelario Franco que los apaches en el parage de "Guacavavi" habian asaltado á un convoy de cinco individuos que se conducian para los pueblos de valle de Batuc, y que solo habia salido a Pivipa el C. Trinidad Franco. En el acto alisté una fuerza de diez hombres montados que al mando del C. Francisco Fimbres salio al lugar del asalto con objeto

131 ReYes, "Estrategias", para la endogamia, pp. 84-87, y sobre la distribución del espacio doméstico, con la observación de corrales en las casas, p. 153.

132 RIA, AGES, $E, P$, t. 427, Sahuaripa, 27 de mayo de 1870. J. N. Cruz, prefecto de Sahuaripa, al secretario de Estado. 
de proteger á los cuatro individuos que quedaron defendiendose en el campo. ${ }^{133}$

El 22 de enero de 1878, en el contexto de una incursión apache, se brindó protección a un convoy que seguía el mismo itinerario que un par de viajeros que poco antes había sido asaltado entre Cumpas y la villa de Moctezuma:

El dia 22 del presente como á las 6 de la tarde recibí aviso de que los bárbaros en número de treinta mas ó menos y en la mesa Ocotillosa á inmediaciones de Gécori[,] asaltaron á los C.C. Jesus Provencio y Cayetano Sanchez (hijo) quedando muerto el $1^{\circ}$ y herido el $2^{\circ}$. Como tan fatal noticia circuló para Cumpas antes de una hora estuvo el C. Francisco Escárcega con cuarenta hombres en el lugar del acontecimiento[,] donde poco despues llegó otra partida que voluntariamente y de momento salió de esta Villa á levantar el cadáver y el herido. [...].134

El papel de la autoridad local al mando de vecinos para proteger un convoy era crucial, como se puede apreciar en el siguiente suceso, que muestra la vulnerabilidad de un grupo considerable, en este caso "una caravana de más de treinta hombres" dedicados al comercio de granos y abarrotes:

El día 19 de este mes, estando en la Magdalena llegó violentamente un ciudadano de la vinatería que esta en el Rancho del

133 RIA, AGES, $E$, $P$, t. 472, Prefectura de Moctezuma, correspondencia de marzo a diciembre, abril de 1876, Moctezuma, 17 de abril de 1876. R. Roman, prefecto de Moctezuma, al gobernador y comandante militar del estado.

134 RIA, AGES, $E$, $P$, t. 467, Ures, 31 de enero de 1878. El prefecto de Moctezuma a J. Quijada, secretario de Estado. 
Alamo, camino para Cucurpe, participando que acababan de atacar los Apaches inmediato a la citada vinatería a una caravana de mas de treinta hombres que venía de Cucurpe con cargamento de granos y otras cosas de abarrote. En aquel momento despaché al Juez $1^{\circ}$ de Paz D. Mariano Valenzuela con treinta hombres de a pié y de a caballo para auxiliar aquella [... ${ }^{135}$

\section{Resguardar la población}

En caso de percatarse de una incursión apache próxima, la autoridad local disponía concentrar las familias en los lugares más seguros, como el templo y el centro del pueblo.

El siguiente suceso que relata el comisario municipal de Pueblo de Álamos, distrito de Ures, lo ejemplifica: puesto que no había fuerzas para rechazar a los apaches que atacaron el pueblo, el comisario tomó la medida de reunir a todas las familias en el centro del mismo, mientras los atacantes incendiaban las casas de las orillas:

Con sentimiento pongo por noticia a VS las desgracias causadas por el bárbaro Apachi en este pueblo pues el veintiuno de éste se encontraron rastros en las orillas de este pueblo en la mañana[,] hago al momento se tome la providencia de despachar mas exploradores y a distancia de un cuarto de legua devisaron a los apaches[,] mandaron el aviso y quedaron otros de vijillas [vigías] para ver el rumbo que tomaban y al momento dispuso el General Dn. Luis Tánori salir violentamente con los pocos hombres que con él pude reunir y luego encontró con

135 RIA, AGES, E, P, t. 303, Prefectura del Distrito de San Ignacio, marzo de 1857, 21 de marzo de 1857. José Elías, prefecto de San Ignacio, al gobernador. 
ellos poniéndole a la vista seis apaches. Siguió tras de ellos con la gente que llevaba[,] creyendo que no eran mas que aquellos porque no se veían mas hasta que al cunbrar al pie de la sierra nombrada del Rancho de los Yaquis se fue levantando la pachería en un grupo muy grande en donde logró el infiel pachi los asesinatos que quiso[,] dando muerte al Gral. Dn. Luis Tánori y once mas que lo acompañaban, [...] y en el mismo día se dirigió la Apacheria para este pueblo y como a las once del día se avistoraron al horía [orilla] de este pueblo y no habiendo fuerzas para rechazarlos tomé la providencia de reunir todas las familias al centro y con los pocos hombres que había para el resguardo de las familias se favoreció el pueblo, entró la apachería a las orillas del pueblo encendiándolo y con unos tiros que se les tiraron no tuvieron campo de lograr su intento y entonces venían entrando dos mujeres y un hombre que venían del Rancho de la Feliciana, lla el entrar al pueblo dieron muerte a los tres, quemaron unas cuantas casas de la horia de éste pueblo[,] animándolos como cuerbería [...], lo que pongo por noticia a VE para que tomándolo en consideración permanezca una fuerza en éste pueblo por hallarse amagado de venganza por el bárbaro apachi, [...] pues no tiene duda que estos pueblo[sic] es fronterizo y resguarda los demás pueblo del interior. ${ }^{136}$

\section{CONSIDERACIONES FINALES}

El papel decisivo de los particulares en la resistencia a las incursiones apaches se confirma para este espacio y lapso. Un número significativo de los reportes indica que son los particulares los que proveen los elementos para realizar las medidas ofensivas y defensivas, como combatientes,

136 RIA, AGES, E, P, t. 283, Álamos, 23 de mayo de 1854. Comisario Municipal de Pueblo de Álamos, Distrito de Ures, al gobernador. 
armas, parque, caballos y víveres. Lo anterior se complementaba con ocasionales trámites de pago o reembolso ante instancias gubernamentales que retribuían las aportaciones hechas en un principio por particulares.

En el ámbito bélico, la Guardia Nacional y los vecinos voluntarios son los actores más importantes numérica y cualitativamente en el contexto de la autodefensa limitada. Son un semillero de líderes políticos, de jefes militares y empresarios regionales y locales, de los que Ignacio Pesqueira es el modelo emblemático. Las autoridades militares de ópatas y pápagos fueron incorporadas a la Guardia Nacional y participaron en la autodefensa limitada para resistir las incursiones de apaches, a cambio de prerrogativas y apoyos, como el respaldo a los pápagos en sus conflictos territoriales con los seris, por lo que la amenaza apache renovó vínculos de los vecinos con los ópatas y los pápagos. ${ }^{137}$

Enfrentar las incursiones apaches dio a los miembros de la Guardia Nacional y a los voluntarios una movilidad horizontal y un conocimiento de las regiones aledañas a sus asentamientos de origen, que no hubieran alcanzado de no haber existido este contexto de violencia. Sus desplazamientos tras los apaches atenuaron el aislamiento de la población común de la región, debido a los accidentes geográficos, las distancias y los extremos del clima, y a las épocas de sequía o de ríos y arroyos torrenciales.

Autodefensa limitada, autoabastecimiento y autonomía política local se reforzaban mutuamente. Para desarticular esta tríada, el gobierno nacional reemplazó el protagonismo

137 RIA, AGES, E, P, t. 426, Altar, 30 de octubre de 1870. Miguel Zepeda, prefecto de Altar, al secretario de Estado. 
de la Guardia Nacional por el del ejército. ${ }^{138}$ Menguada la vía de hacer méritos sirviendo cercana y visiblemente a los vecindarios, la autonomía política local se debilitó.

El ejército federal se tornó relevante a partir de 1890 por contar con una presencia permanente y móvil en Sonora, por disponer de guarniciones fortificadas, por comunicarse por el telégrafo y el ferrocarril, y coincide con el afianzamiento del control de la población nativa del otro lado de la frontera por el ejército estadounidense, por lo que las incursiones apaches a México se tornaron esporádicas y circunscritas. ${ }^{139}$ Cabe reconocer que a lo largo del siglo xIx hubo una presencia reducida de efectivos del ejército nacional en el fuerte de Fronteras en los periodos durante los cuales estuvieron ahí asentados apaches de paz. ${ }^{140}$

Los pápagos, que era el único grupo que podía cruzar la frontera en persecución de los apaches, debido a que contaban con la prerrogativa de cruzar la "línea" en ambas direcciones, ${ }^{141}$ declinaron en su papel antagónico frente a los apaches.

Las autoridades menores -en cuanto a demarcaciones, como el celador, los comisarios de policía y los jueces locales- encabezaban la operación de las medidas ofensivas, coordinaban la Guardia Nacional, informaban al presidente

138 Almada Bay, Lorta, Domínguez y Contreras, "El papel de los vecinos".

139 RIA, AGES, $I-A$, t. 14, exp. 10, ff. 10437-10438, 14 de junio de 1895. R. Aragón, prefecto de Moctezuma al secretario de estado, Hermosillo.

140 RIA, AGES, $E, P$, t. 334, ramo militar perteneciente al estado de Sonora, 12 de septiembre de 1850. Gabriel García, comandante del fuerte militar de Fronteras al gobernador de Sonora.

${ }^{141}$ RIA, AGES, $E$, $P$, t. 416, s.e., s. f., Altar, 13 de mayo de 1869. Miguel Zepeda, prefecto de Altar, al secretario de Estado, Ures. 
municipal o al prefecto sobre los incidentes ocurridos y las disposiciones tomadas, gestionaban recursos y, frecuentemente, conducían las partidas de vecinos que salían en "persecución" inmediatamente después de recibir el aviso de una incursión apache. ${ }^{142}$ La participación de estas autoridades locales se explica, en parte, porque sus familias y bienes se veían afectados por las incursiones apaches y estaban vinculadas al vecindario por lazos de parentesco. Territorialidad y comunidad eran fuerzas cohesivas en los pequeños asentamientos. ${ }^{143}$

La existencia de desertores y de negativas a prestar auxilios descarta una sociedad de vecinos sin fisuras, y hace patente cómo la resistencia a las incursiones apaches no era compartida de manera homogénea. Las respuestas variaban según los asentamientos y los distritos. Influía la devolución o la paga de bienes prestados con anterioridad a la Guardia Nacional por el gobierno del estado. Si bien la disposición general era de cooperar, en ocasiones se expresaba una oposición justificada por un cálculo del resultado que podía ser adverso, como expusieron los vecinos de Bacoachi al prefecto de Arizpe:

142 RIA, AGES, E, $P$, t. 365, 1875, Moctezuma, Correspondencia de enero a diciembre, abril de 1875, Moctezuma, 1ํ de abril de 1875. J. Aragón, prefecto de Moctezuma, al secretario de Estado.

${ }^{143}$ En marzo de 1857 el juez primero local del rancho del Álamo, Mariano Valenzuela, informó al prefecto de San Ygnacio del ataque de una partida de apaches a una caravana de más de treinta hombres, reportando que "según dicen los pocos que salieron debe haber mas muertos pues faltan once, y entre ellos dos hermanos míos y el resto primos hermanos". RIA, AGES, $E, P$, t. 303, Prefectura del Distrito de San Ignacio, Marzo de 1857, 21 de marzo de 1857. 
Tan luego como me presenté en el pueblo de Bacoachi, aquellos habitantes me hicieron varias manifestaciones, asegurandome que su mente no fue negarle los auxilios al Gobierno; cuando se les llamó por esta Prefectura, si no el de representar se les considerara según el estado de miseria de su población y poco numero de habitantes, a la vez que tenian noticias, que a muy cortas distancias habia rancherias de Apaches: que por lo expuesto se reusaron, pero que siempre reconocen y obedecen las disposiciones del Gobierno y demas autoridades, por lo que estaban prontos a lo que se les ordene.

Esta prefectura considerando aquellos ciudadanos por las demostraciones de obediencia que han tenido según mi adjunto parte, y que de hecho estan castigados, siendo su pequeño numero de habitantes un baluarte contra las incursiones de los barbaros: por lo que recomiendo a VE admita las justas disculpas que interponen aquellos ciudadanos en los cuales no encuentra otros principios subversivos esta Prefectura. ${ }^{144}$

El arribo a Sonora del Estado-nación con sus funciones básicas - pacificar, poblar, comunicar y homogenizar- terminó con las incursiones apaches -en coincidencia de intereses con el ejército y el gobierno estadounidenses-, desmovilizó la Guardia Nacional, y la cohesión de los pueblos se erosionó por la incorporación de connacionales y extranjeros y el impacto de las grandes inversiones estadounidenses en la minería y el ferrocarril, que abrieron oportunidades de empleo y de migración, y por la ausencia de un enemigo externo común, dando lugar al asedio de la autonomía municipal y de las tierras en manos de nativos y a desajustes

144 RIA, AGES, E, P, t. 324, Prefectura del Distrito de Arizpe. Marzo de 1858, Arizpe, 2 de marzo de 1858. Santiago García, prefecto de Arizpe, al "[...] Gobernador del Estado. Donde se halle". 
sociales y económicos. En esta región así cristalizó la transformación de la frontera con los nómadas independientes en una frontera con Estados Unidos. ${ }^{145}$

\section{SIGLAS Y REFERENCIAS}

AGES Archivo General del Estado de Sonora.

AGES, E, P, Archivo General del Estado de Sonora, fondo Ejecutivo, ramo Prefectura.

AGES, E, I Archivo General del Estado de Sonora, fondo Ejecutivo, ramo Indígenas.

AHAH, E Archivo Histórico del Arzobispado de Hermosillo, Sonora, fondo Eclesiástico.

AHAH, $A$ y $G$ Archivo Histórico del Arzobispado de Hermosillo, Sonora, fondo Administración y Gobierno.

CIS-BELY Centro INAH Sonora. Biblioteca Ernesto López Yescas, Archivo Parroquial.

RIA Respuestas a las Incursiones Apaches.

Almada, Francisco R.

Diccionario de bistoria, geografía y biografía sonorenses, Hermosillo, Instituto Sonorense de Cultura, 2009.

Almada Bay, Ignacio

"La saca. Una práctica retributiva en una frontera caracterizada por la informalidad y la violencia. Sonora, 1851-1870”, en Rojas y DeEds (coords.), 2014, pp. 563-590.

"Ilícitos, solidaridades y tradiciones locales en la construcción de una identidad territorial en la frontera norte de México. Sonora ¿una tierra de excepción? La perspectiva de antiguo régimen”, en SARIEgo Rodríguez (comp.), 2008, pp. 203-238.

145 KATz, La guerra secreta, pp. 23-40; TInker, A la sombra, pp. 152-360. 
Almada Bay, Ignacio y Alejandro Luna Navarro

Sonora. Historia de las instituciones jurídicas, t. I, Siglo XIX, México, Universidad Nacional Autónoma de México, Senado de la República, 2010.

Sonora. Historia de las instituciones jurídicas, t. II, Siglos XXXXI, México, Universidad Nacional Autónoma de México, Senado de la República, 2012.

Almada Bay, Ignacio, Juan Carlos Lorta, David Contreras y Amparo Angélica Reyes Gutiérrez

"Casos de despueble de asentamientos atribuidos a apaches en Sonora, 1852-1883. Un acercamiento a los efectos de las incursiones apaches en la población de vecinos" [en prensa].

Almada Bay, Ignacio, Juan Carlos Lorta, Valeria Domínguez y David Contreras

"El papel de los vecinos del distrito de Moctezuma, Sonora, en la campaña de Crawford, 1885-1886. Un punto de inflexión en las respuestas a las incursiones apaches", en Medina Bustos y Padilla Calderón (coords.), 2013, pp. 197-233.

Alonso, Ana María

Thread of Blood. Colonialism, Revolution, and Gender on Mexico's Northern Frontier, Tucson, The University of Arizona Press, 1995.

Base

Base de datos "Respuestas a las Incursiones Apaches (RIA)" http://sahuaro.colson.edu.mx:8087/RIApublico/Principal.aspx

Base de datos “Testamentos de Sonora” http://www.colson. edu.mx:8080/testamentos/principal.aspx

Bernabéu Albert et al. (coords.)

La indianización. Cautivos, renegados, "hommes libres" $y$ misioneros en los confines americanos (s. XVI-XIX), Madrid, Ediciones Doce Calles, École des Hautes Études en Sciences Sociales, 2012. 
Borrero Silva, María del Valle y Dénica Velarde Cadena

"Las compañías de ópatas de la provincia de Sonora", en Medina Bustos y Padilla Calderón (coords.), 2013, pp. 95-114.

\section{Colonias Militares}

Colonias Militares. Proyecto para su establecimiento en las fronteras de oriente y occidente de la República, México, Imprenta de I. Cumplido, 1848.

Chevalier, François

"Survivances seigneuriales et présages de la révolution agraire dans le nord du Mexique (fin du XVIII et XIX ${ }^{\mathrm{e}}$ siécles)", en Revue Historique, ccxxiI, 1959, pp. 1-18.

Chust, Manuel y Juan Marchena Fernández (eds.)

Las armas de la nación. Independencia y ciudadanía en Hispanoamérica (1750-1850), Madrid, Iberoamericana, Vervuert, 2007.

Chust, Manuel y José Antonio Serrano Ortega

“Milicia y revolución liberal en España y México", en Chust y Marchena Fernández (eds.), 2007, pp. 82-110.

DeLay, Brian

War of A Thousand Deserts. Indian Raids and the U.S.-Mexican War, New Haven, Yale University Press, 2008.

García, Luis A.

"Bárbaros, presidios, milicias y frontera: Un estudio del noreste novohispano durante el siglo XviII", en Artemio BenAviDEs Hinojosa (coord.), Sociedad, milicia y política en Nuevo León. Siglos XVIII y XIX. Homenaje al historiador Isidro Viscaya Canales (1917-2005), Monterrey, Archivo General del Estado de Nuevo León, 2005, pp. 163-213. 
GAYOL, Víctor

"Las milicias nacionales en la construcción del Estado-Nación en España e Hispanoamérica, siglo xix: hacia un balance historiográfico", en Ruiz Iвá̃̃EZ (coord.), 2009, pp. 460-480.

Gonzalbo, Pilar

Vivir en Nueva España. Orden y desorden en la vida cotidiana, México, El Colegio de México, 2009.

Griffen, William B.

Apaches at War and Peace. The Janos Presidio, 1750-1858, Albuquerque, University of New Mexico, 1988a.

Utmost Good Faith. Patterns of Apache-Mexican Hostilities in Northern Chibuabua Border Warfare, 1821-1848, Albuquerque, University of New Mexico, 1988b.

Hernández Chávez, Alicia

"La Guardia Nacional en la construcción del orden republicano", en Chust y Marchena (eds.), 2007, pp. 224-246.

Jасову, Karl

Shadows at Dawn: A Borderlands Massacre and the Violence of History, Nueva York, Penguin Press, 2008.

KaTZ, Friedrich

La guerra secreta en México. 1. Europa, Estados Unidos y la revolución mexicana, México, Era, 1982.

León Figueroa, Norma Guadalupe de

El conflicto apache en Sonora bajo el gobierno del general Ignacio Pesqueira, 1867-1872, Hermosillo, El Colegio de Sonora, Colegio de Bachilleres del Estado de Sonora, 2012.

LLoyd, Jane-Dale

"Milicias pueblerinas: el surgimiento de una cultura de guerra en las comunidades agrarias fronterizas decimonónicas", en Lloyd y Pérez Rosales (coords.), 2010, pp. 89-127. 
Lloyd, Jane-Dale y Laura Pérez Rosales (coords.)

Proyectos políticos, revueltas populares y represión oficial en México, 1821-1965, México, Universidad Iberoamericana, 2010.

Medina Bustos, José Marcos y Esther Padilla Calderón (coords.)

Indios, españoles y mestizos en zonas de frontera, siglos XVII$X X$, Hermosillo, El Colegio de Sonora, El Colegio de Michoacán, 2013.

Reglamento

Reglamento para el establecimiento de las Colonias Militares en la frontera del norte, México, diciembre de 1868, México, Imprenta del Gobierno en Palacio, a cargo de José M. Sandoval, 1869, Universidad Autónoma de Nuevo León, http://cdigital.dgb.uanl.mx/la/1080078059/1080078059.PDF

Reyes Gutiérrez, Amparo Angélica

"Estrategias de organización y recomposición de las familias de la frontera durante la Guerra Apache, Sonora, 1852-1872", tesis de maestría en ciencias sociales, Sonora, El Colegio de Sonora, 2012.

Rodríguez, Martha

La guerra entre bárbaros y civilizados: el exterminio del nómada en Coabuila, 1840-1880, Saltillo, Centro de Estudios Sociales y Humanísticos, 1998.

Rojas, Laura y Susan DeEds (coords.)

México a la luz de sus revoluciones, México, El Colegio de México, 2014, vol. 1.

Ruiz IbÁÑ̃z, José Javier (coord.)

Las milicias del rey de España, Madrid, Fondo de Cultura Económica, 2009. 
Sánchez Moreno, Francisco Javier

“La indianización de la guerra contra los ‘bárbaros’ en el noreste de México", en VII Seminario de la Escuela de Ciencias Sociales de la Universidad Autónoma de Coabuila. Mentalidades y vida cotidiana, Antología II, Saltillo, Escuela de Ciencias Sociales, 2013.

"Apolinario Moreno. Cautivo de los comanches y prisionero en México”, en Bernabéu Albert et al. (coords.), 2012, pp. 85-106.

SARIego Rodríguez, José Luis (comp.)

El Norte de México: entre fronteras, México, Instituto Nacional de Antropología e Historia, 2008.

Shelton, Laura

For Tranquility and Order. Family and Community on Mexico's Northern Frontier, 1800-1850, Tucson, The University of Arizona Press, 2010.

Sheridan, Thomas E.

Arizona. A History, Tucson, The University of Arizona Press, 1995.

Smith, Ralph A.

“The Scalp Hunter in the Borderlands 1835-1850”, en Arizona and the West. A Quarterly Journal of History, 6: 1 (primavera 1964), pp. 5-22.

"Indians in American-Mexican Relations before the War of 1846", en The Hispanic American Historical Review, 43: 1 (1963), pp. 34-64.

Sweeney, Edwin R.

Mangas Coloradas. Chief of the Chiricahua Apaches, Norman, University of Oklahoma Press, 1998.

From Cochise to Geronimo. The Chiricabua Apaches, 18741886, Norman, University of Oklahoma Press, 2010. 
Tinker Salas, Miguel

A la sombra de las águilas. Sonora y la transformación de la frontera durante el porfiriato, México, Fondo de Cultura Económica, El Colegio de Sonora, Universidad Autónoma de Sinaloa, 2010.

Torre Curiel, José Refugio de la

"Comerciantes, precios y salarios en Sonora en el periodo colonial tardío. Caracterización de un circuito comercial cautivo", en Historia Mexicana, Lx:2 (230) (oct.-dic. 2008), pp. 595-656.

Trejo Contreras, Zulema

Redes, facciones y liberalismo. Sonora, 1850-1876, Hermosillo, El Colegio de Sonora, El Colegio de Michoacán, 2012.

VANDERVORT, Bruce

Indian Wars of Mexico, Canada and the United States, 18121900, Nueva York, Routledge, 2006.

VILLA, Eduardo W.

Compendio de historia del estado de Sonora, México, Patria Nueva, 1937.

West, Robert C.

Sonora. Its Geographical Personality, Austin, University of Texas Press, 1993.

White, Richard

The Middle Ground. Indians, Empires, and Republics in the Great Lakes Region, 1650-1815, Cambridge, Cambridge University Press, 1999.

Yetman, David A.

The Ópatas. In Search of a Sonoran People, Tucson, The University of Arizona Press, 2010. 
